\title{
Stack Modeling of a Molten Carbonate Fuel Cell (MCFC)
}

\begin{tabular}{|c|c|}
\hline Journal: & Fuel Cells \\
\hline Manuscript ID: & fuce. $200900174 . R 1$ \\
\hline Wiley - Manuscript type: & Original Research Paper \\
\hline $\begin{array}{r}\text { Date Submitted by the } \\
\text { Author: }\end{array}$ & 11-Jan-2010 \\
\hline Complete List of Authors: & $\begin{array}{l}\text { Pfafferodt, Matthias; Otto von Guericke University, Chair for Process } \\
\text { Systems Engineering } \\
\text { Heidebrecht, Peter; Max-Planck-Institut } \\
\text { Sundmacher, Kai; Max-Planck-Institut; Otto von Guericke } \\
\text { University, Chair for Process Systems Engineering }\end{array}$ \\
\hline Keywords: & $\begin{array}{l}\text { Molten Carbonate Fuel Cell, Numerical Simulation, Internal } \\
\text { Reforming, High Temperature, Mathematical Modeling, MCFC, FEM }\end{array}$ \\
\hline
\end{tabular}

\section{$\$$ ScholarONE \\ Manuscript Central}




\title{
Stack Modeling of a Molten Carbonate Fuel Cell (MCFC)
}

\author{
Matthias Pfafferodt ${ }^{1}$, Peter Heidebrecht ${ }^{2}$, and Kai Sundmacher ${ }^{1,2, *}$ \\ ${ }^{1}$ Process Systems Engineering, Otto von Guericke University Magdeburg, Universitätsplatz \\ 2, 39106 Magdeburg, Germany \\ ${ }^{2}$ Max Planck Institute for Dynamics of Complex Technical Systems, Sandtorstrasse 1, 39106 \\ Magdeburg, Germany
}

Received

[] Corresponding author: sundmacher@mpi-magdeburg.mpg.de

\begin{abstract}
A model of a Molten Carbonate Fuel Cell (MCFC) stack including internal steam reforming is presented. It comprises a symmetric section of the stack, consisting of one half Indirect Internal Reforming unit (IIR) and four fuel cells. The model describes the gas phase compositions, the gas and solid temperatures and the current density distribution within the highly integrated system. The model assumptions, the differential equations and boundary conditions as well as the coupling equations used in the model are shown. The strategy to solve the system of partial differential equations is outlined. The simulation result show that the fuel cells within the stack operate at different temperatures. This is expected to have an impact on the voltages as well as the degradation rates within the individual fuel cells.
\end{abstract}

Keywords: Molten Carbonate Fuel Cell, MCFC, Numerical Simulation, Internal Reforming, High Temperature, Mathematical Modeling, FEM

\section{Introduction}

Fuel cells are an efficient technology for the generation of electric power. The Molten Carbonate Fuel Cell (MCFC) - a high temperature fuel cell - is suitable for the co-production of electricity and high-graded heat in stationary applications [1]. A power plant technology based on the MCFC principle, the so-called HotModule, is developed and manufactured by the MTU Onsite Energy in Ottobrunn, Germany [2].

The temperature is an important state variable for the operation of high temperature fuel cells such as the MCFC [3]. Within an MCFC system, the temperature is typically at about $600^{\circ} \mathrm{C}$. This is high enough to allow for internal reforming, the production of hydrogen from different types of fuels such as natural gas, waste gas or gas from bio mass fermentation [4]. Also, no expensive catalysts are required due to the high temperatures; nickel and nickel oxide are sufficiently active to be used as reforming catalyst and electrode catalysts.

The temperature field in the MCFC is determined by several interacting processes. The steam reforming process is endothermic, thus it constitutes a heat sink. In contrast, the electrochemical reactions at both electrodes as well as the ion transport through the electrolyte produce heat. Energy is transported convectively by anode and cathode gases and is conducted in the solid parts of the cell stack. The anodic and cathodic gas flows constitute directed heat transport mechanisms, while the heat conduction is an omnidirectional heat transport mechanism. Together, these processes generate a spatially distributed temperature profile. For an efficient and economically competitive operation, this temperature profile has 
to be within a certain temperature window. Too low temperatures decrease the local reaction rates and the ion conductivity, thus decreasing the cell voltage and thereby resulting in low efficiency. Too high temperatures cause fast degradation of the catalyst material, thus reducing the system's life time.

The direct measurement of the temperature profile within the fuel cell system, especially inside the fuel cell stack, is extremely difficult and unreliable. The high temperature, the aggressive atmosphere within the stack due to the molten carbonate electrolyte and the need for electric isolation of the sensors are the main problems regarding temperature measurements. Therefore, mathematical modeling and numerical simulation have to be applied to estimate the steady state and dynamical temperature profiles.

The HotModule has a cross-flow configuration of the anode and cathode gas channels. Thus, for an adequate description of the temperature profiles within each fuel cell, at least a 2D model of the cell plane is needed. Furthermore, if the temperature profile perpendicular to the cell plane should be taken into account, one has to consider the stack length as a third coordinate.

Within the literature different models exists for molten carbonate fuel cells. The complexity of the models varies from a lumped representation of the fuel cell stack [5,6] over the simulation of a small 3D cutout section of one cell [7] to models of one fuel cell, taking into account the 3D geometry [8] or a simplified 2D representation of the cell plane [9-13]. An agglomerate model where the volume averaged stack is simulated was presented by Brouwer et. al. [14]. The models are used to analyze the system states within the fuel cell, especially the temperatures, the (spatially distributed) current density and the cell voltage. Furthermore, these models allow the development of suitable temperature control strategies $[5,6,15]$ or the optimization of design parameters such as the catalyst distribution within the MCFC stack [16].

The model discussed in this manuscript is an extension of the single cell model presented first by Heidebrecht and Sundmacher [12]. That model has been validated by Gundermann et al. based on experimental data collected at an industrial scale MCFC plant [13,17]. In contrast to that previous model, the stack model presented here considers all tree spatial directions, including one half of an Indirect Internal Reforming unit (IIR) and four fuel cells.

Especially this reforming unit, which is inserted into the stack at certain positions, causes significant temperature gradients in stack direction and discriminates this stack model from previous ones. The 3D structure of the MCFC stack is described using two spatial coordinates for the fuel cell plane and implementing the heat exchange in the third direction along the stack length via source terms in the corresponding equations.

\section{Working principle}

The working principle of a Molten Carbonate Fuel Cell is shown in Fig. 1. The fuel cell is assembled in a planar structure. The electrodes are porous metallic structures and a eutectic molten carbonate salt is used as electrolyte. Above the anode and below the cathode, gas channels are located, through which the gaseous reaction educts and products are transported. A reforming catalyst is placed into the anode channels for Direct Internal Reforming (DIR). An additional gas channel is attached to the fuel cell. It contains reforming catalyst for Indirect Internal Reforming and is referred to as "reforming unit" [18].

The typical fuel gas of an MCFC system mainly consists of methane and steam. This gas mixture has to be reformed prior to electrochemical conversion. Both, the methane steam reforming reaction (ref1) and the water gas shift reaction (ref2) are taken into account in the model:

$$
\mathrm{CH}_{4}+\mathrm{H}_{2} \mathrm{O} \Leftrightarrow \mathrm{CO}+3 \mathrm{H}_{2}
$$


A part of the methane steam reforming is performed outside the fuel cell stack in an external reformer, which is not included in this model. From there, the gas mixture containing methane, water, hydrogen, carbon monoxide and carbon dioxide is transported into the reforming unit. This gas compartment is thermally coupled to the fuel cell. Thereby, the heat needed for the endothermic reforming process is directly provided by the electrochemical reactions within the neighboring fuel cell [19]. At typical MCFC temperatures, conversion in the reforming unit is limited by the corresponding chemical equilibrium.

The effluent from the reforming unit is redirected into the anode gas channel. Within the anode gas compartment, not only the reforming reactions ((ref1) and (ref2)) have to be taken into account, but also the electrochemical oxidation of hydrogen (ox1) and carbon monoxide (ox2). They react with carbonate ions from the electrolyte to water, carbon dioxide and electrons:

$$
\begin{aligned}
& \mathrm{H}_{2}+\mathrm{CO}_{3}^{2-} \Leftrightarrow \mathrm{CO}_{2}+\mathrm{H}_{2} \mathrm{O}+2 e^{-} \\
& \mathrm{CO}+\mathrm{CO}_{3}^{2-} \Leftrightarrow 2 \mathrm{CO}_{2}+2 e^{-}
\end{aligned}
$$

The reforming reactions ((ref1) and (ref2)) within the anode channel are not only thermally coupled to the electrochemical reactions. Due to the continuous removal of hydrogen and carbon monoxide, the equilibrium limited reforming process is pushed to almost complete conversion of methane.

The anode exhaust gas is mixed with air and completely burned in the catalytic combustion chamber. Because air is fed in excess, the exhaust gas of the combustion chamber still contains a significant amount of oxygen. This gas is redirected into the cathode channel, where the electrochemical reduction (red) takes place. New carbonate ions are produced from carbon dioxide, oxygen and two electrons according to the backwards directions of the following cathode reaction

$$
\mathrm{CO}_{3}^{2-} \Leftrightarrow \mathrm{CO}_{2}+\frac{1}{2} \mathrm{O}_{2}+2 e^{-}
$$

The carbonate ions are transported to the anode through the electrolyte. The electrochemical reactions at the anode act as an electron source while the electrochemical reaction at the cathode acts as an electron sink. Both are connected via an electric load and thus the fuel cell serves as an electric energy supply device.

In the HotModule, one part of the cathode exhaust gas is recycled to the catalytic combustion chamber while the rest of the gas leaves the fuel cell system.

\section{MCFC Stack Model}

Within the HotModule MCFC power plant, 343 fuel cells and 42 IIR units are arranged in a fuel cell stack. A repeating pattern formed by 8 fuel cells with an active cell area of approximately $1 \mathrm{~m}^{2}$ followed by one reforming unit is used. Under two assumptions, the stack behavior can be represented by a symmetric section consisting of four fuel cells and one half Indirect Internal Reforming unit. The first assumption neglects thermal effects at both ends of the stack. The second assumption says that the sequence of anode and cathode channels along the stack direction has no significant impact on the temperature profile. The structure of this so-called symmetric stack model is shown in Fig. 2.

The Indirect Internal Reforming unit is attached to the first fuel cell. It is arranged in a counter flow configuration compared to the anode gas compartments. In each fuel cell, the 
anode and the cathode gas channels are oriented to each other in a cross flow configuration. The solid components of each fuel cell, the electrolyte, the electrolyte matrix and the channel walls, are combined in the solid phase. In addition to the above mentioned components, the model includes the heat exchanger, the catalytic combustion chamber and the reversal chamber. These auxiliary components are common for all cells in the HotModule system.

The gas flow directions within the symmetric stack model are indicated in Fig. 2. The feed gas $(I N)$, which is assumed to have passed through the external reformer, is heated up in the heat exchanger ( $H E A)$ by the hot gas from the catalytic combustion chamber and flows into the reforming unit (IIR, reforming reactions (ref1) and (ref2)). After that, the gas flow is splitted into four equal parts which are redirected into the anode compartments $(A)$ of the fuel cells (reforming reactions (ref1) and (ref2); oxidation reactions (ox1) and (ox2)). The exhaust gases of the four anode gas compartments are mixed with the cathode gas recycle $(R E C)$ and completely burned with air $(A I R)$ in the catalytic combustion chamber $(B)$. After that, the gas goes into the reversal chamber $(R C)$, where the blower is located. The gas is redirected into the second chamber of the heat exchanger ( $H E B$ ). Within the heat exchanger, the energy of the gas is used to heat up the feed gas. In the next step, the gas flow is equally splitted to the cathode gas compartments of the four fuel cells ( $C$, reduction reaction (red)). A part of the cathode exhaust gas is used in the cathode gas recycle $(R E C)$, which is redirected into the catalytic combustion chamber $(B)$, while the rest leaves the fuel cell system (OUT).

In addition to the coupling of the different compartments by the convective mass flow, they are also thermally coupled in stack direction. Furthermore, the electrochemical reaction rates at both electrodes of each fuel cell are coupled via the charge balance.

To achieve a more general description that is also valid for equivalent systems, the complete symmetric stack model is formulated in terms of dimensionless variables. The definition of the most important dimensionless variables is shown in Table 1. A complete list of all dimensionless variables is included in the work of Heidebrecht [11].

\subsection{General Assumptions}

The presented symmetric stack model is an extension of the model proposed by Heidebrecht et al. [11,12]. It is based on partial and total mass balances as well as enthalpy and charge balances. One purpose of the symmetric stack model is to simulate load change scenarios, thus it is formulated in transient equations.

The main assumptions applied to the modeling of the symmetric MCFC stack are:

- Ideal gas behavior.

- Isobaric conditions.

- Symmetric boundary conditions at both ends of the symmetric model in stack direction.

- All solid parts of a fuel cell are combined into one single solid phase with an average heat conductivity and a cumulative heat capacity.

- There are no concentration, temperature or velocity gradients perpendicular to the cell plane within the different parts of the symmetric stack model. This assumption corresponds to plug flow conditions within the gas compartments and reduces the geometry of the reforming unit, the anode and cathode gas compartments as well as the solid phase to two spatial dimensions. The heat and mass transport between the different parts along the stack length are represented as exchange terms in the corresponding balance equations.

- Gas compositions in the channels of the Indirect Internal Reforming unit and the anode gas compartment are usually close to the chemical equilibrium of the reforming reactions. Therefore, power law kinetics are applied to describe their reaction rates. The kinetics of the electrochemical reactions are described by Butler-Volmer equations [12]. 
- The heat capacity of the gas mixture depends on the molar fractions, $\chi_{i}$, but not on the temperature. The heat capacities, $c_{\mathrm{p}, i}$, of the pure components are calculated at a reference temperature of $T^{r}=600{ }^{\circ} \mathrm{C}$, corresponding to a dimensionless temperature of $\vartheta^{r}=2.93$.

$$
\overline{c_{\mathrm{p}}}=\sum_{i} \chi_{i} c_{\mathrm{p}, i} \text { with } c_{\mathrm{p}, i}=c_{\mathrm{p}, i}\left(\vartheta^{r}\right)=\text { const }
$$

- The electric potentials of each cell are independent from the potentials of the neighboring fuel cells. This is equivalent to the assumption that in each bipolar plate between two cells, complete equilibration of the electric potential is achieved. This is a proper assumption if the neighboring cells show similar current density profiles. In that case only small currents occur along the plane of the bipolar plates, resulting in a virtually constant potential in each bipolar plate. The validity of this assumption will be checked carefully using the simulation results (see Section 5.2).

\subsection{Governing Equations}

In the following, all equations needed to describe the symmetric stack model are presented. The definition a single fuel cell model is based on previous works $[11,12,16]$. The equations for the anode, the solid and the cathode are adapted and the changes are shown. For a detailed derivation of these model equations, especially the equations for the reaction kinetics and the thermodynamic expressions, we refer to the corresponding publications. Within the symmetric stack model, equations for the heat exchanger and the two-phase model for the reforming unit are added. Furthermore, the heat transport between the different gas compartments along the stack direction is implemented.

The symmetric stack model can be used for an arbitrary number of fuel cells, specified by $n_{\text {cells }}$. The standard configuration includes four fuel cells and one half reforming unit, a combination which is currently used in industrial fuel cell stacks.

\subsubsection{Feed gas}

The feed gas ( IN ) for the MCFC system is assumed to be a partially reformed gas from an external reformer. The composition, $\chi_{i, I N}$, the temperature, $\vartheta_{I N}$, and the molar flux, $\Gamma_{I N}$, of the feed gas are input parameters of the symmetric stack model. They are given in Table 2 (Section 5) for the simulated load case.

\subsubsection{Heat exchanger (side A)}

The gas is heated up in a heat exchanger $(H E A)$ before it reaches the reforming unit. The exhaust gas from the catalytic combustion chamber passes the hot side of the heat exchanger. This gas chamber of the heat exchanger is modeled as a spatially lumped tank. The component mass fraction, $\chi_{i, H E A}$, the gas temperature, $\vartheta_{H E A}$, and the total molar flow, $\Gamma_{H E A}$, are calculated from the following equations:

$$
\frac{V_{H E A}}{\vartheta_{H E A}} \frac{\partial \chi_{i, H E A}}{\partial \tau}=\Gamma_{I N} \cdot\left(\chi_{i, I N}-\chi_{i, H E A}\right)
$$




$$
\begin{aligned}
& \frac{V_{H E A}}{\vartheta_{H E A}} \frac{\partial \vartheta_{H E A}}{\partial \tau}=\Gamma_{I N} \frac{\bar{c}_{\mathrm{p}_{I N}}}{{\overline{\mathrm{p}_{H E A}}}_{\mathrm{p}_{H N}}} \cdot\left(\vartheta_{I N}-\vartheta_{H E A}\right)-\frac{Q_{H E}}{\overline{\overline{\mathrm{p}}_{H E A}}} \\
& \Gamma_{H E A}=\Gamma_{I N} \cdot\left(1+\frac{\bar{c}_{\mathrm{p}_{I N}}}{{\overline{\mathrm{p}_{\text {}}}}_{H E A}} \cdot\left(\frac{\vartheta_{I N}}{\vartheta_{H E A}}-1\right)\right)-\frac{Q_{H E}}{\overline{\overline{\mathrm{p}}_{H E A}} \vartheta_{H E A}}
\end{aligned}
$$

The heat exchanged between the two gas chambers of the heat exchanger, $Q_{H E}$, depends on the temperature difference between the two gas flows and is given by

$$
Q_{H E}=S t_{H E} \cdot\left(\vartheta_{H E A}-\vartheta_{H E B}\right)
$$

\subsubsection{Indirect Internal Reforming unit}

A detailed analysis of the actual design of the Indirect Internal Reforming unit (IIR) showed that the reforming reactions are mass transport limited [18]. In [20], we report these findings in detail and derive a reduced model that is used in this symmetric stack model. The basic structure of the model for the reforming unit is shown in Fig. 3. The model describes one non-reactive phase (upper index $N$ ) and one reactive phase (upper index $R$ ) which exchange mass and heat across the interface between them (upper index $I$ ). In the nonreactive phase, the gas is convectively moving in the negative $\zeta_{1}$-direction, while the gas in the reactive phase is stagnant and is subject to homogeneous reforming reactions.

The volume of the reforming catalyst pellets (upper index $P$ ) is taken into account as a dead volume within the reactive phase. The volume fractions of the non-reactive phase, the reactive phase and the catalyst pellets phase sum up to unity:

$$
1=\varepsilon_{I I R}^{N}+\varepsilon_{I I R}^{R}+\varepsilon_{I I R}^{P}
$$

Due to the fact that the catalyst pellets are completely surrounded by the reactive phase, the area fraction for the heat exchange between this gas phase of the reforming unit and the solid phase of the neighboring fuel cell is given by $\left(\varepsilon_{I I R}^{R}+\varepsilon_{I I R}^{P}\right)$, while for the non-reactive phase, $\varepsilon_{I I R}^{N}$ is used.

The component mass balances (Eq. (7)) and the energy balance (Eq. (8)) describe the molar fraction, $\chi_{i, I I R}^{N}$, and the temperature, $\vartheta_{I I R}^{N}$, within the non-reactive phase:

$$
\begin{aligned}
& \varepsilon_{I I R}^{N} \frac{V_{I I R}}{\vartheta_{I I R}^{N}} \frac{\partial \chi_{i, I I R}^{N}}{\partial \tau}=-\varepsilon_{I I R}^{N} \gamma_{I I R}^{N} \frac{\partial \chi_{i, I I R}^{N}}{\partial \zeta_{1}}-n_{i, I I R}^{I}-\chi_{i, I I R}^{N} n_{t, I I R}^{I} \\
& \varepsilon_{I I R}^{N} \frac{V_{I I R}}{\vartheta_{I I R}^{N}} \frac{\partial \vartheta_{I I R}^{N}}{\partial \tau}=-\varepsilon_{I I R}^{N} \gamma_{I I R}^{N} \frac{\partial \vartheta_{I I R}^{N}}{\partial \zeta_{1}}+\frac{1}{\bar{c}_{\mathrm{p}_{I I R}}^{N}} \cdot\left(\left(\sum_{i} n_{i, I I R}^{I-} c_{\mathrm{p}_{i}}\right) \cdot\left(\vartheta_{I I R}^{N}-\vartheta_{I I R}^{R}\right)-q_{I I R}^{I}+\varepsilon_{I I R}^{N} q_{I I R S}^{N}\right)
\end{aligned}
$$

$n_{i, I I R}^{I}$ is the mass flux density across the interface between the reactive and the non-reactive phases and $q_{I I R}^{I}$ denotes the interface heat flux density. The heat flux density between the non-reactive gas phase within the reforming unit and the solid of the neighboring fuel cell is 
represented by $q_{I I R S}^{N}$. It is multiplied by the corresponding area fraction, $\varepsilon_{I I R}^{N}$, to account for the reduced exchange area. Both equations contain a convective term along the main flow direction (negative $\zeta_{1}$-direction).

The molar flow density within the reforming unit, $\gamma_{I I R}^{N}$, is always negative. It is described by the following equation:

$$
0=-\frac{\partial\left(\varepsilon_{I I R}^{N} \gamma_{I I R}^{N} \vartheta_{I I R}^{N}\right)}{\partial \zeta_{1}}+\frac{1}{{\overline{\mathrm{p}_{I I R}}}^{N}} \cdot\left(\left(\sum_{i} n_{i, I I R}^{I-} c_{\mathrm{p}_{i}}\right) \cdot\left(\vartheta_{I I R}^{N}-\vartheta_{I I R}^{R}\right)-q_{I I R}^{I}+\varepsilon_{I I R}^{N} q_{I I R S}^{N}\right)+\vartheta_{I I R}^{N} n_{t, I I R}^{I}(9)
$$

The molar fraction, $\chi_{i, I I R}^{R}$, and the temperature, $\vartheta_{I I R}^{R}$, within the reactive phase are calculated using Eq. (10) and Eq. (11), respectively:

$$
\begin{aligned}
& \varepsilon_{I I R}^{R} \frac{V_{I I R}}{\vartheta_{I I R}^{R}} \frac{\partial \chi_{i, I I R}^{R}}{\partial \tau}=n_{i, I I R}^{I}-\chi_{i, I I R}^{R} n_{i, I I R}^{I}+\varepsilon_{I I R}^{R} \cdot\left(\sum_{j=r e f}\left(v_{i, j}-\chi_{i, I I R}^{R} \bar{v}_{j}\right) D a_{j, I I R} r_{j, I I R}\right)
\end{aligned}
$$

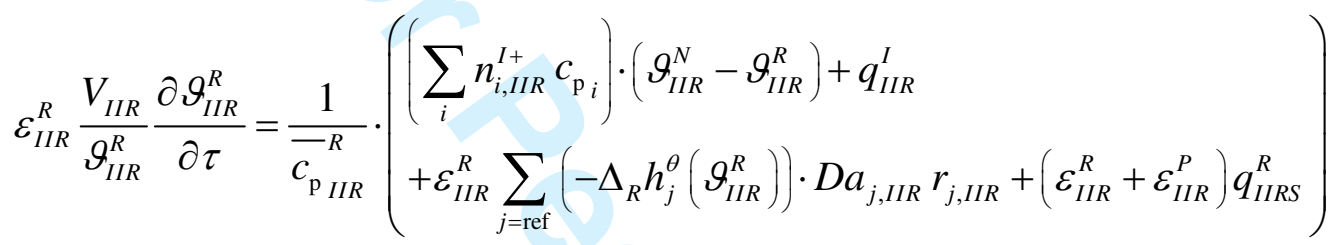

The heat flux density between the reactive phase and the solid phase of the neighboring fuel cell is given by $q_{I I R S}^{R}$. The exchange area is taken into account using the corresponding area ratio $\left(\varepsilon_{I I R}^{R}+\varepsilon_{I I R}^{P}\right)$.

For Eqs. (7) to (9), the necessary boundary conditions correspond to the inlet conditions of the non-reactive phase:

$$
\begin{aligned}
& \chi_{i, I I R}^{N}\left(\zeta_{1}=1, \zeta_{2}, \tau\right)=\chi_{i, I I R, i n}^{N}=\chi_{i, H E A} \\
& \vartheta_{I I R}^{N}\left(\zeta_{1}=1, \zeta_{2}, \tau\right)=\vartheta_{I I R, \text { in }}^{N}=\vartheta_{H E A} \\
& \gamma_{I I R}^{N}\left(\zeta_{1}=1, \zeta_{2}, \tau\right)=\gamma_{I I R, \text { in }}^{N}=-\frac{\Gamma_{H E A}}{\varepsilon^{N}}
\end{aligned}
$$

As the convective flow in the reforming unit is in negative $\zeta_{1}$-direction, a negative sign for the molar flow density occurs in Eq. (14).

At the outlet of the reforming unit, the average outlet concentrations, $\chi_{i, I I R, \text { out }}$, the average outlet temperature, $\vartheta_{I I R, \text { out }}$, and the total outlet molar flow, $\Gamma_{I I R, \text { out }}$, are calculated:

$$
\begin{aligned}
& \Gamma_{I I R, \text { out }} \chi_{i, I I R, \text { out }}=\int_{0}^{1}\left[-\varepsilon^{N} \gamma_{I I R}^{N} \chi_{i, I I R}^{N}\right]_{\zeta_{1}=0, \zeta_{2}} \mathrm{~d} \zeta_{2} \\
& \Gamma_{I I R, \text { out }} \bar{c}_{\mathrm{p}_{\text {IIR,out }}} \cdot\left(\vartheta_{I I R, \text { out }}-\vartheta^{r}\right)=\int_{0}^{1}\left[-\varepsilon^{N} \gamma_{I I R}^{N}{\overline{\mathrm{p}_{I I R}}}^{N} \cdot\left(\vartheta_{I I R}^{N}-\vartheta^{r}\right)\right]_{\zeta_{1}=0, \zeta_{2}} \mathrm{~d} \zeta_{2} \\
& \Gamma_{I I R, \text { out }}=\int_{0}^{1}\left[-\varepsilon^{N} \gamma_{I I R}^{N}\right]_{\zeta_{1}=0, \zeta_{2}} \mathrm{~d} \zeta_{2}
\end{aligned}
$$


The mass flux density across the two-phase interface requires detailed consideration. The component molar flux, $n_{i, I I R}^{I}$, is composed of a convective term:

$$
n_{i, I I R}^{I}=n_{i, I I R, c o n v}^{I}+n_{i, I I R, d i f f}^{I}
$$

For the diffusive component molar flux, $n_{i, I I R, \text { diff }}^{I}$, linear transport kinetics are used

$$
n_{i, I I R, d i f f}^{I}=D_{i, I I R}^{I} \cdot\left(\chi_{i, I I R}^{N}-\chi_{i, I I R}^{R}\right)
$$

with $D_{i, I I R}^{I}$ as the mass transport coefficient across the interface. These coefficients can also be interpreted as Stanton numbers of mass transport.

The total molar flux across the interface, $n_{t, I I R}^{I}$, plus the change in mole numbers due to the reforming reactions have to compensate the expansion effect in the reactive phase due to dynamic temperature changes. At steady state, the right hand side of Eq. (20) equals zero.

$$
n_{t, I I R}^{I}+\varepsilon_{I I R}^{R} \sum_{j=\mathrm{ref}} \bar{v}_{j} D a_{j, I I R} r_{j, I I R}=-\frac{1}{\vartheta_{I I R}^{R} \bar{c}_{\mathrm{p}_{I I R}}^{R}} \cdot\left(\begin{array}{l}
\left(\sum_{i} n_{i, I I R}^{I+} c_{\mathrm{p}_{i}}\right) \cdot\left(\vartheta_{I I R}^{N}-\vartheta_{I I R}^{R}\right)+q_{I I R}^{I} \\
+\varepsilon_{I I R}^{R} \sum_{j=\mathrm{ref}}\left(-\Delta_{R} h_{j}^{0}\left(\vartheta_{I I R}^{R}\right)\right) \cdot D a_{j, I I R} r_{j, I I R} \\
+\left(\varepsilon_{I I R}^{R}+\varepsilon_{I I R}^{P}\right) q_{I I R S}^{R}
\end{array}\right)
$$

The difference between the total molar flux, $n_{t, I I R}^{I}$, and the sum of the diffusive component molar fluxes, $n_{i, I I R \text {,diff }}^{I}$, is compensated by the total convective flux at the interface, $n_{t, I I R, \text { conv }}^{I}$. The sum of the diffusive component fluxes is not equal to zero due to the fact that molar fluxes are used.

$$
n_{t, I I R, \text { conv }}^{I}=n_{t, I I R}^{I}-\sum_{i} n_{i, I I R, d i f f}^{I}
$$

The partial convective flux of species $i$ is calculated from the total convective flux taking into account an average molar fraction of species $i$ at the interface.

$$
n_{i, I I R, \mathrm{conv}}^{I}=n_{t, I I R, \mathrm{conv}}^{I} \frac{\chi_{i, I I R}^{N}+\chi_{i, I I R}^{R}}{2}
$$

The following expressions are used in the enthalpy equations of the non-reactive and reactive phase (Eqs. (8) and (11)).

$$
n_{i, I I R}^{I+}=\left\{\begin{array}{r}
n_{i, I I R}^{I}, \text { if } n_{i, I I R}^{I}>0 \\
0, \text { if } n_{i, I I R}^{I} \leq 0
\end{array} ; \quad n_{i, I I R}^{I-}=\left\{\begin{array}{r}
0, \text { if } n_{i, I I R}^{I}>0 \\
n_{i, I I R}^{I}, \text { if } n_{i, I I R}^{I} \leq 0
\end{array}\right.\right.
$$


A linear approach is used for the heat flux between the non-reactive phase and the reactive phase as well as for the heat fluxes between both gas phases and the solid phase of the neighboring first fuel cell:

$$
\begin{aligned}
& q_{I I R}^{I}=S t_{I I R}^{I} \cdot\left(\vartheta_{I I R}^{N}-\vartheta_{I I R}^{R}\right) \\
& q_{I I R S}^{N}=S t_{I I R S}^{N} \cdot\left(\vartheta_{S}^{(1)}-\vartheta_{I I R}^{N}\right) \\
& q_{I I R S}^{R}=S t_{I I R S}^{R} \cdot\left(\vartheta_{S}^{(1)}-\vartheta_{I I R}^{R}\right)
\end{aligned}
$$

Within the first fuel cell, the total heat flux density between the reforming unit and the solid phase is needed (Eq. (71) in Section 3.2.10). It is calculated from the heat flux densities in the reactive and the non-reactive phase, accounting for the corresponding area fractions:

$$
q_{S, I I R}=\varepsilon_{I I R}^{N} q_{I I R S}^{N}+\left(\varepsilon_{I I R}^{R}+\varepsilon_{I I R}^{P}\right) q_{I I R S}^{R}
$$

\subsubsection{Anode gas phase}

One anode gas phase $(A)$ has to be modeled for each of the four fuel cells. The upper index $k$ is used to identify the number of the actual fuel cell. In the anode channels, both reforming reactions ((ref1) and (ref2)) as well as both electrochemical oxidation reactions ((ox1) and (ox2)) are considered. The component molar fractions, $\chi_{i, A}^{(k)}$, the temperature, $\vartheta_{A}^{(k)}$, and the molar flux density, $\gamma_{A}^{(k)}$, are given by the component mass balance (Eq. (28)), the energy balance (Eq. (29)) and the total mass balance (Eq. (30)).

$$
\begin{aligned}
& \frac{V_{A}}{\vartheta_{A}^{(k)}} \frac{\partial \chi_{i, A}^{(k)}}{\partial \tau}=-\gamma_{A}^{(k)} \frac{\mathrm{d} \chi_{i, A}^{(k)}}{\mathrm{d} \zeta_{1}}+n_{i, A S}^{(k)}-\chi_{i, A}^{(k)} \sum_{l} n_{l, A S}^{(k)}+\sum_{j=\mathrm{ref}}\left(v_{i, j}-\chi_{i, A}^{(k)} \bar{v}_{j}\right) \cdot D a_{j, A} r_{j, A}^{(k)}(28) \\
& \frac{V_{A}}{\vartheta_{A}^{(k)}} \frac{\partial \vartheta_{A}^{(k)}}{\partial \tau}=-\gamma_{A}^{(k)} \frac{\mathrm{d} \vartheta_{A}^{(k)}}{\mathrm{d} \zeta_{1}}+\frac{1}{\bar{c}_{\mathrm{p}_{A}}^{(k)}} \cdot\left(\begin{array}{l}
\left(\sum_{i} n_{i, A S}^{(k)+} c_{\mathrm{p}_{i}}\right) \cdot\left(\vartheta_{S}^{(k)}-\vartheta_{A}^{(k)}\right) \\
+\sum_{j=\mathrm{ref}}\left(-\Delta_{R} h_{j}^{\theta}\left(\vartheta_{A}^{(k)}\right)\right) \cdot D a_{j, A} r_{j, A}^{(k)}+q_{A S}^{(k)}
\end{array}\right) \\
& 0=-\frac{\mathrm{d}\left(\gamma_{A}^{(k)} \vartheta_{A}^{(k)}\right)}{\mathrm{d} \zeta_{1}}+\frac{1}{\bar{c}_{\mathrm{p}_{A}}^{(k)}} \cdot\left(\begin{array}{l}
\left(\sum_{i} n_{i, A S}^{(k)+} c_{\mathrm{p}_{i}}\right) \cdot\left(\vartheta_{S}^{(k)}-\vartheta_{A}^{(k)}\right) \\
\left.+\sum_{j=\mathrm{ref}}\left(-\Delta_{R} h_{j}^{\theta}\left(\vartheta_{A}^{(k)}\right)\right) \cdot D a_{j, A} r_{j, A}^{(k)}+q_{A S}^{(k)}\right)
\end{array}\right) \\
& +\vartheta_{A}^{(k)} \sum_{i} n_{i, A S}^{(k)}+\vartheta_{A}^{(k)} \sum_{j=\mathrm{ref}} \bar{v}_{j} D a_{j, A} r_{j, A}^{(k)}
\end{aligned}
$$

Within these equations, $n_{i, A S}^{(k)}$ denotes the component mass flux density between the anode gas channels and the anode pores. It is defined using linear mass transport kinetics:

$$
\begin{aligned}
& n_{i, A S}^{(k)}=D_{i, A S} \cdot\left(\varphi_{i, A C}^{(k)}-\chi_{i, A}^{(k)}\right) \\
& n_{i, A S}^{(k)+}=\left\{\begin{array}{r}
n_{i, A S}^{(k)}, \text { if } n_{i, A S}^{(k)}>0 \\
0, \text { if } n_{i, A S}^{(k)} \leq 0
\end{array}\right.
\end{aligned}
$$


where $\phi_{i, A C}^{(k)}$ denotes the gas composition inside the electrode pores in terms of partial pressures. It is described in more detail in Section 3.2.9.

The heat flux density between the anode gas channels and the solid phase, $q_{A S}^{(k)}$, depends on the temperature difference between these phases:

$$
q_{A S}^{(k)}=S t_{A S} \cdot\left(\vartheta_{S}^{(k)}-\vartheta_{A}^{(k)}\right)
$$

The gas from the reforming unit is equally distributed to all fuel cells. The boundary conditions for the molar fractions, the temperature and the molar flow density are given by

$$
\begin{aligned}
& \chi_{i, A}^{(k)}\left(\zeta_{1}=0, \zeta_{2}, \tau\right)=\chi_{i, A, \text { in }}^{(k)}=\chi_{i, I I R, \text { out }} \\
& \vartheta_{A}^{(k)}\left(\zeta_{1}=0, \zeta_{2}, \tau\right)=\vartheta_{A, \text { in }}^{(k)}=\vartheta_{I I R, \text { out }} \\
& \gamma_{A}^{(k)}\left(\zeta_{1}=0, \zeta_{2}, \tau\right)=\gamma_{A, \text { in }}^{(k)}=\frac{\Gamma_{I I R, \text { out }}}{n_{\text {cells }}} \\
& \text { for } k=1, \ldots, n_{\text {cells }}
\end{aligned}
$$

At the anode outlets, average values for the molar fractions, $\chi_{i, A, \text { out }}$, and the temperature, $\vartheta_{A, \text { out }}$, as well as for the total molar flow of the exhaust gas, $\Gamma_{A, \text { out }}$, are needed. They are calculated using similar equations as used at the outlet of the reforming unit (Eqs. (15) to (17)), but a summation over all cells is added.

$$
\begin{aligned}
& \Gamma_{A, \text { out }} \chi_{i, A, \text { out }}=\sum_{k=1}^{n_{\text {cells }}} \int_{0}^{1}\left[\gamma_{A}^{(k)} \chi_{i, A}^{(k)}\right]_{\zeta_{1}=1, \zeta_{2}} \mathrm{~d} \zeta_{2} \\
& \Gamma_{A, \text { out }} \bar{c}_{\mathrm{p}_{A, \text { out }}} \cdot\left(\vartheta_{A, \text { out }}-\vartheta^{r}\right)=\sum_{k=1}^{n_{\text {cells }}} \int_{0}^{1}\left[\gamma_{A}^{(k)} \bar{c}_{\mathrm{p}_{A}}^{(k)} \cdot\left(\vartheta_{A}^{(k)}-\vartheta^{r}\right)\right]_{\zeta_{1}=1, \zeta_{2}} \mathrm{~d} \zeta_{2} \\
& \Gamma_{A, \text { out }}=\sum_{k=1}^{n_{\text {cells }}} \int_{0}^{1}\left[\gamma_{A}^{(k)}\right]_{\zeta_{1}=1, \zeta_{2}} \mathrm{~d} \zeta_{2}
\end{aligned}
$$

\subsubsection{Catalytic combustion chamber}

Within the catalytic combustion chamber ( $B)$, the anode exhaust gas (index $A$, out ) is mixed with air $(A I R)$ and the gas from the cathode gas recycle $(R E C)$. Furthermore, all nonoxidized components of the gas are fully oxidized.

$$
\begin{aligned}
& \Gamma_{B} \chi_{i, B}=\sum_{l} \Gamma_{l} \cdot\left(\chi_{i, l}+\sum_{j=c o m b} v_{i, C_{j}} \chi_{j, l}\right) \\
& \Gamma_{B} \overline{c_{\mathrm{p}_{B}}} \cdot\left(\vartheta_{B}-\vartheta^{r}\right)=\sum_{l} \Gamma_{l} \cdot\left(\overline{c_{\mathrm{p}}} \cdot\left(\vartheta_{l}-\vartheta^{r}\right)+\sum_{i} \chi_{i, l} \cdot\left(-\Delta_{C} h_{i}^{\theta}\left(\vartheta^{r}\right)\right)\right) \\
& \Gamma_{B}=\sum_{l} \Gamma_{l} \cdot\left(1+\sum_{j=\text { comb }} \bar{v}_{C_{j}} \chi_{j, l}\right) \\
& \quad \text { for } \quad l=A, \text { out } ; R E C ; A I R
\end{aligned}
$$


The temperature of the air, $\vartheta_{A I R}$, its composition, $\chi_{i, A I R}$, as well as the total molar flow of the air, $\Gamma_{A I R}$, are input parameters of the model (see Table 2 in Section 5).

\subsubsection{Reversal chamber}

The reversal chamber $(R C)$ is a large process volume located between the catalytic combustion chamber and the second chamber of the heat exchanger. For simplicity, it is modeled as a well-mixed tank similar to the modeling of the heat exchangers.

$$
\begin{aligned}
& \frac{V_{R C}}{\vartheta_{R C}} \frac{\partial \chi_{i, R C}}{\partial \tau}=\Gamma_{B} \cdot\left(\chi_{i, B}-\chi_{i, R C}\right) \\
& \frac{V_{R C}}{\vartheta_{R C}} \frac{\partial \vartheta_{R C}}{\partial \tau}=\Gamma_{B} \frac{\overline{\bar{p}_{B}}}{\overline{c_{\mathrm{p}_{R C}}}} \cdot\left(\vartheta_{B}-\vartheta_{R C}\right)-\frac{Q_{R C}}{\overline{c_{\mathrm{p}_{R C}}}}+\frac{P_{\text {blower }}}{\overline{c_{\mathrm{p}_{R C}}}} \\
& \Gamma_{R C}=\Gamma_{B} \cdot\left(1+\frac{\overline{\mathrm{p}_{B}}}{\overline{c_{\mathrm{p}_{R C}}}} \cdot\left(\frac{\vartheta_{B}}{\vartheta_{R C}}-1\right)\right)-\frac{Q_{R C}}{\overline{c_{\mathrm{p}_{R C}}} \vartheta_{R C}}+\frac{P_{\text {blower }}}{\overline{c_{\mathrm{p}_{R C}}} \vartheta_{R C}}
\end{aligned}
$$

Within the reversal chamber, the energy input of the gas blower, $P_{\text {blower }}$, as well as the heat loss to the environment, $Q_{R A C}$, are taken into account. For the heat loss, $Q_{R A C}$, a linear approach is used

$$
Q_{R C}=S t_{R C} \cdot\left(\vartheta_{R C}-\vartheta_{U}\right)
$$

while the energy input due to the gas blower, $P_{\text {blower }}$, is listed in Table 2 as an input parameter.

\subsubsection{Heat exchanger (side B)}

The hot side of the heat exchanger ( $H E B)$ is located behind the reversal chamber and before the cathode gas compartments. It is modeled using similar equations as for the cold side of the heat exchanger (Section 3.2.2).

$$
\begin{aligned}
& \frac{V_{H E B}}{\vartheta_{H E B}} \frac{\partial \chi_{i, H E B}}{\partial \tau}=\Gamma_{R C} \cdot\left(\chi_{i, H E B}-\chi_{i, H E B}\right) \\
& \frac{V_{H E B}}{\vartheta_{H E B}} \frac{\partial \vartheta_{H E B}}{\partial \tau}=\Gamma_{R A C} \frac{\bar{c}_{\mathrm{p}_{R C}}}{{\overline{\mathrm{p}_{H E B}}}_{\mathrm{p}_{H E B}}} \cdot\left(\vartheta_{R C}-\vartheta_{H E B}\right)+\frac{Q_{H E}}{\overline{c_{\mathrm{p}_{H E B}}}} \\
& \Gamma_{H E B}=\Gamma_{R C} \cdot\left(1+\frac{\bar{c}_{\mathrm{p}_{R C}}}{{\overline{\mathrm{p}_{H E B}}}_{H E B}} \cdot\left(\frac{\vartheta_{R C}}{\vartheta_{H E B}}-1\right)\right)+\frac{Q_{H E}}{\overline{\overline{\mathrm{p}}_{H E B}} \vartheta_{H E B}}
\end{aligned}
$$

The heat flux between the two chambers of the heat exchanger, $Q_{H E}$, is described in Eq. (5).

\subsubsection{Cathode gas phase}


The cathode gas phase $(C)$ is modeled in full analogy to the anode gas phase. Because anode and cathode gas flow are arranged in cross flow, the main gas flow direction in the cathode follows the second spatial coordinate, $\zeta_{2}$. The electrochemical reduction (red) is the only reaction considered here. Eqs. (50) to (52) describe the molar fractions, $\chi_{i, C}^{(k)}$, the temperature, $\vartheta_{C}^{(k)}$, and the molar flow, $\gamma_{C}^{(k)}$, within the cathode channels.

$$
\begin{aligned}
& \frac{V_{C}}{\vartheta_{C}^{(k)}} \frac{\partial \chi_{i, C}^{(k)}}{\partial \tau}=-\gamma_{C}^{(k)} \frac{\mathrm{d} \chi_{i, C}^{(k)}}{\mathrm{d} \zeta_{2}}+\left[n_{i, C S}^{(k)}-\chi_{i, C}^{(k)} \sum_{l} n_{l, C S}^{(k)}\right] \\
& \frac{V_{C}}{\vartheta_{C}^{(k)}} \frac{\partial \vartheta_{C}^{(k)}}{\partial \tau}=-\gamma_{C}^{(k)} \frac{\mathrm{d} \vartheta_{C}^{(k)}}{\mathrm{d} \zeta_{2}}+\frac{1}{\bar{c}_{\mathrm{p}_{C}}^{(k)}} \cdot\left(\left(\sum_{i} n_{i, C S}^{(k)+} c_{\mathrm{p}_{i}}\right) \cdot\left(\vartheta_{S}^{(k)}-\vartheta_{C}^{(k)}\right)+q_{C S}^{(k)}\right) \\
& 0=-\frac{\mathrm{d}\left(\gamma_{C}^{(k)} \vartheta_{C}^{(k)}\right)}{\mathrm{d} \zeta_{2}}+\frac{1}{\bar{c}_{\mathrm{p}_{C}}^{(k)}} \cdot\left(\left(\sum_{i} n_{i, C S}^{(k)+} c_{\mathrm{p}_{i}}\right) \cdot\left(\vartheta_{S}^{(k)}-\vartheta_{C}^{(k)}\right)+q_{C S}^{(k)}\right)+\vartheta_{C}^{(k)} \sum_{i} n_{i, C S}^{(k)}
\end{aligned}
$$

For the mass transport to the electrode pores as well as for the boundary conditions and the calculation of average values at the outlets, similar equations as for the anode (Eqs. (31) to (39)) are used.

The molar flow density from the electrode pores is defined as

$$
\begin{aligned}
& n_{i, C S}^{(k)}=D_{i, C S} \cdot\left(\varphi_{i, C C}^{(k)}-\chi_{i, C}^{(k)}\right) \\
& n_{i, C S}^{(k)+}=\left\{\begin{array}{r}
n_{i, C S}^{(k)}, \text { if } n_{i, C S}^{(k)}>0 \\
0, \text { if } n_{i, C S}^{(k)} \leq 0
\end{array}\right.
\end{aligned}
$$

The heat exchange density between the anode and the solid phase is given by:

$$
q_{C S}^{(k)}=S t_{C S} \cdot\left(\vartheta_{S}^{(k)}-\vartheta_{C}^{(k)}\right)
$$

For the inlet boundary conditions, the properties of the gas flow from the reversal chamber are used. The gas flow is equally distributed to all cathodes.

$$
\begin{aligned}
& \chi_{i, C}^{(k)}\left(\zeta_{1}, \zeta_{2}=0, \tau\right)=\chi_{i, C, i n}^{(k)}=\chi_{i, H E B} \\
& \vartheta_{C}^{(k)}\left(\zeta_{1}, \zeta_{2}=0, \tau\right)=\vartheta_{C, \text { in }}^{(k)}=\vartheta_{H E B} \\
& \gamma_{C}^{(k)}\left(\zeta_{1}, \zeta_{2}=0, \tau\right)=\gamma_{C, \text { in }}^{(k)}=\frac{\Gamma_{H E B}}{n_{\text {cells }}} \\
& \text { for } k=1, \ldots, n_{\text {cells }}
\end{aligned}
$$

At the outlets, average values for the composition of the gas, $\chi_{i, C, \text { out }}$, and the temperature of the gas, $\vartheta_{C, \text { out }}$, as well as for the total molar flow, $\Gamma_{C, \text { out }}$, are calculated:

$$
\Gamma_{C, \text { out }} \chi_{i, C, \text { out }}=\sum_{k=1}^{n_{\text {cells }}} \int_{0}^{1}\left[\gamma_{C}^{(k)} \chi_{i, C}^{(k)}\right]_{\zeta_{1}, \zeta_{2}=1} \mathrm{~d} \zeta_{1}
$$




$$
\begin{aligned}
& \Gamma_{C, \text { out }} \bar{c}_{\mathrm{p}_{C, \text { out }}} \cdot\left(\vartheta_{C, \text { out }}-\vartheta^{r}\right)=\sum_{k=1}^{n_{\text {cells }}} \int_{0}^{1}\left[\gamma_{C}^{(k)} \bar{c}_{\mathrm{p}_{C}}^{(k)} \cdot\left(\vartheta_{C}^{(k)}-\vartheta^{r}\right)\right]_{\zeta_{1}, \zeta_{2}=1} \mathrm{~d} \zeta_{1} \\
& \Gamma_{C, \text { out }}=\sum_{k=1}^{n_{\text {cells }}} \int_{0}^{1}\left[\gamma_{C}^{(k)}\right]_{\zeta_{1}, \zeta_{2}=1} \mathrm{~d} \zeta_{1}
\end{aligned}
$$

A part of the cathode exhaust gas is recycled ( $R E C$ ). The cathode gas recycle ratio, $f_{R E C}$, determines the gas fraction of cathode exhaust gas that is redirected towards the catalytic combustion chamber (see Section 3.2.5). The value used for $f_{R E C}$ is given in Table 2.

$$
\begin{aligned}
& \chi_{i, R E C}=\chi_{i, C, \text { out }} \\
& \vartheta_{R E C}=\vartheta_{C, \text { out }} \\
& \Gamma_{R E C}=f_{R E C} \Gamma_{C, \text { out }}
\end{aligned}
$$

\subsubsection{Electrode pores}

Within the electrode pores, the electrochemical reactions take place. The spatial distribution of the gas composition along the pore is neglected and an integral mass balance is used to describe the partial pressure of the components, $\varphi_{i, A C}^{(k)}$ and $\varphi_{i, C C}^{(k)}$, in the pores of the corresponding electrodes:

$$
\begin{aligned}
& \frac{V_{A C}}{\vartheta_{S}^{(k)}} \frac{\partial \varphi_{i, A C}^{(k)}}{\partial \tau}=\sum_{j=\mathrm{ox}} v_{i, j} D a_{j, A C} r_{j, A C}^{(k)}-n_{i, A S}^{(k)} \\
& \frac{V_{C C}}{\vartheta_{S}^{(k)}} \frac{\partial \varphi_{i, C C}^{(k)}}{\partial \tau}=\sum_{j=\mathrm{red}} v_{i, j} D a_{j, C C} r_{j, C C}^{(k)}-n_{i, C S}^{(k)}
\end{aligned}
$$

The component mass flux between the gas channels and the electrode pores, $n_{i, A S}^{(k)}$ and $n_{i, C S}^{(k)}$, are given in Eq. (31) and Eq. (53), respectively. Regarding the enthalpy balance, the electrode pores are considered as part of the solid phase (see Section 3.2.10).

\subsubsection{Solid phase}

The enthalpy balance within the solid phase ( $S$ ) of each fuel cell (Eq. (67)) considers heat conduction along the cell plane, enthalpy exchange due to mass exchange with the gas channels, non-convective heat exchange with the gas phases $\left(q_{A S}^{(k)}\right.$ and $\left.q_{C S}^{(k)}\right)$, heat source terms due to electrochemical reactions and ion conduction $\left(q_{S, \text { cell }}^{(k)}\right)$ and heat exchange along the stack.

$$
\begin{aligned}
c_{\mathrm{p}_{S}} \frac{\partial \vartheta_{S}^{(k)}}{\partial \tau} & =\frac{l_{2}}{P e_{S}} \frac{\partial^{2} \vartheta_{S}^{(k)}}{\partial \zeta_{1}^{2}}+\frac{1}{P e_{S} l_{2}} \frac{\partial^{2} \vartheta_{S}^{(k)}}{\partial \zeta_{2}^{2}}+\left(\sum_{i}\left(-n_{i, A S}^{(k)-}\right) c_{\mathrm{p}_{i}}\right) \cdot\left(\vartheta_{A}^{(k)}-\vartheta_{S}^{(k)}\right) \\
& +\left(\sum_{i}\left(-n_{i, C S}^{(k)-}\right) c_{\mathrm{p}_{i}}\right) \cdot\left(\vartheta_{C}^{(k)}-\vartheta_{S}^{(k)}\right)-q_{A S}^{(k)}-q_{C S}^{(k)}+q_{S, \text { cell }}^{(k)}+q_{S, \text { stack }}^{(k)}
\end{aligned}
$$

The molar flux densities from the anode gas channels to the solid phase are given by 


$$
n_{i, A S}^{(k)-}=\left\{\begin{array}{r}
0, \text { if } n_{i, A S}^{(k)}>0 \\
n_{i, A S}^{(k)}, \text { if } n_{i, A S}^{(k)} \leq 0
\end{array}\right.
$$

and for the cathode gas channels an analogous equation is used

$$
n_{i, C S}^{(k)-}=\left\{\begin{array}{r}
0, \text { if } n_{i, C S}^{(k)}>0 \\
n_{i, C S}^{(k)}, \text { if } n_{i, C S}^{(k)} \leq 0
\end{array}\right.
$$

The heat source density within the solid phase, $q_{S \text {, cell }}$, includes the heat production due to the electrochemical reactions as well as the heat production due to the ion conduction:

$$
\begin{aligned}
q_{S, \text { cell }}^{(k)} & =\sum_{j=\mathrm{ox}}\left(-\Delta_{R} h_{j}^{\theta}\left(\vartheta_{S}^{(k)}\right)+n_{j} \cdot\left(\phi_{A}^{S(k)}-\phi_{A}^{L(k)}\right)\right) \cdot D a_{j, A C} r_{j, A C}^{(k)} \\
& +\sum_{j=\mathrm{red}}\left(-\Delta_{R} h_{j}^{\theta}\left(\vartheta_{S}^{(k)}\right)+n_{j} \cdot\left(\phi_{C}^{S(k)}-\phi_{C}^{L(k)}\right)\right) \cdot D a_{j, C C} r_{j, C C}^{(k)} \\
& +\left(\phi_{A}^{L(k)}-\phi_{C}^{L(k)}\right) i_{E}^{(k)} \frac{1}{F}
\end{aligned}
$$

The heat exchange in stack direction, $q_{S, \text { stack }}^{(k)}$, depends on the location of the fuel cell within the symmetric stack model, i.e.:

$$
q_{S, \text { stack }}^{(k)}=\left\{\begin{array}{c}
q_{S, I I R}-q_{S, \text { conn }}^{(k),(k+1)}, \text { if } k=1 \\
q_{S, \text { conn }(k)}^{(k-1)}-q_{S, \text { conn }}^{(k),(k+1)}, \text { if } 1<k<n_{\text {cells }} \\
q_{S, \text { conn }}^{(k-1),(k)}, \text { if } \quad k=n_{\text {cells }}
\end{array}\right.
$$

Eq. (71) shows that each fuel cell is connected to its two neighboring fuel cells. Taking into account the symmetric boundary conditions on both sides of the symmetric stack model, the reforming unit is directly connected to the first fuel cell, while the last fuel cell is only connected to its predecessor.

The heat exchange between the solid phases of two neighboring fuel cells, $q_{S, c o n n}^{(m),(n)}$, depends on the temperature difference between the corresponding solid phases

$$
q_{S, c o n n}^{(m),(n)}=S t_{S} \cdot\left(\vartheta_{S}^{(m)}-\vartheta_{S}^{(n)}\right)
$$

The heat flux density between the reforming unit and the first fuel cell, $q_{S, I I R}$, is given in Eq. (27).

\subsubsection{Electric potential}

The description of the electric potential field is of essential importance for the determination of the current density distribution. For each cell, the dynamic charge balances at both charged double layers are set up and combined with a discretized form of the Poisson equation. 


$$
\begin{aligned}
& \phi_{A}^{S(k)}=0 \\
& \frac{\partial \phi_{A}^{L(k)}}{\partial \tau}=-\frac{1}{c_{A}} \cdot\left(i^{(k)}-i_{A}^{(k)}\right) \\
& \frac{\partial \phi_{C}^{L(k)}}{\partial \tau}=-\frac{1}{c_{A}} \cdot\left(i^{(k)}-i_{A}^{(k)}\right)-\frac{1}{c_{E}} \cdot\left(i^{(k)}-i_{E}^{(k)}\right) \\
& \frac{\mathrm{d} \phi_{C}^{S(k)}}{\mathrm{d} \tau}=\frac{I_{\text {cell }}^{(k)}-I_{A}^{(k)}}{c_{A}}+\frac{I_{\text {cell }}^{(k)}-I_{E}^{(k)}}{c_{E}}+\frac{I_{\text {cell }}^{(k)}-I_{C}^{(k)}}{c_{C}}
\end{aligned}
$$

The specific currents and current densities at the anode, within the electrolyte and at the cathode are given by the kinetics of the electrochemical reactions (Eq. (78) and (82)) and the ion conduction within the electrolyte (Eq. (80)):

$$
\begin{aligned}
& I_{A}^{(k)}=\int i_{A}^{(k)} \mathrm{d} \zeta \\
& i_{A}^{(k)}\left(\phi_{A}^{S(k)}, \phi_{A}^{L(k)}\right)=\sum_{j=\mathrm{ox}} n_{j} F D a_{j, A C} r_{j, A C}^{(k)}\left(\phi_{A}^{S(k)}, \phi_{A}^{L(k)}\right) \\
& I_{E}^{(k)}=\int i_{E}^{(k)} \mathrm{d} \zeta \\
& i_{E}^{(k)}\left(\phi_{A}^{L(k)}, \phi_{C}^{L(k)}\right)=\kappa_{E} \cdot\left(\phi_{A}^{L(k)}-\phi_{C}^{L(k)}\right) \\
& I_{C}^{(k)}=\int i_{C}^{(k)} \mathrm{d} \zeta \\
& i_{C}^{(k)}\left(\phi_{C}^{L(k)}, \phi_{C}^{S(k)}\right)=-\sum_{j=\mathrm{red}} n_{j} F D a_{j, C C} r_{j, C C}^{(k)}\left(\phi_{C}^{S(k)}, \phi_{C}^{L(k)}\right)
\end{aligned}
$$

with $r_{j, A C}^{(k)}$ and $r_{j, C C}^{(k)}$ representing the Butler-Volmer kinetics in the corresponding electrodes (see Section 3.2.12).

Using the specific currents and current densities, the current density distribution of one fuel cell is calculated as:

$$
i^{(k)}=\left(\frac{1}{c_{A}}+\frac{1}{c_{E}}+\frac{1}{c_{C}}\right) \cdot\left(\frac{i_{A}^{(k)}}{c_{A}}+\frac{i_{E}^{(k)}}{c_{E}}+\frac{i_{C}^{(k)}}{c_{C}}-\frac{I_{A}^{(k)}}{c_{A}}-\frac{I_{E}^{(k)}}{c_{E}}-\frac{I_{C}^{(k)}}{c_{C}}\right)+I_{\text {cell }}^{(k)}
$$

The cell voltage is the electric potential difference between the cathode and anode solid phase, while the voltage of the entire stack model is given as the sum of all cell voltages:

$$
\begin{aligned}
& U_{\text {cell }}^{(k)}=\phi_{C}^{S(k)}-\phi_{A}^{S(k)}=\phi_{C}^{S(k)} \\
& U_{\text {stack }}=\sum_{k} U_{c e l l}^{(k)}
\end{aligned}
$$

\subsubsection{Reaction Kinetics}

In the symmetric stack model two types of reactions are considered. One the one hand, the methane steam reforming (ref1) and the water gas shift reaction (ref2) within the reactive phase of the reforming unit and within the anode gas compartment are described by a simple power law approach including an Arrhenius term. These reactions are typically close to their chemical equilibrium. 
On the other hand, Butler-Volmer kinetics are used for the electrochemical oxidation of hydrogen (ox 1) and carbon monoxide (ox2) at the anode

$$
\begin{gathered}
r_{o x 1}^{(k)}=\exp \left(A r r_{o x 1} \cdot\left(\frac{1}{\vartheta_{o x 1}^{\theta}}-\frac{1}{\vartheta_{S}^{(k)}}\right)\right) \cdot\left\{\begin{array}{c}
\varphi_{H_{2}, A C}^{(k)} \exp \left(\alpha_{o x 1,+} n_{o x 1} \frac{\Delta \phi_{A, o x 1}^{(k)}}{\vartheta_{S}^{(k)}}\right) \\
-\varphi_{H_{2} O, A C}^{(k)} \varphi_{C O_{2}, A C}^{(k)} \exp \left(-\left(1-\alpha_{o x 1,+}\right) n_{o x 1} \frac{\Delta \phi_{A, o x 1}^{(k)}}{\vartheta_{S}^{(k)}}\right)
\end{array}\right\} \\
r_{o x 2}^{(k)}=\exp \left(A r r_{o x 2} \cdot\left(\frac{1}{\vartheta_{o x 2}^{\theta}}-\frac{1}{\vartheta_{S}^{(k)}}\right)\right) \cdot\left\{\begin{array}{c}
\varphi_{C O, A C}^{(k)} \exp \left(\alpha_{o x 2,+} n_{o x 2} \frac{\Delta \phi_{A, o x 2}^{(k)}}{\vartheta_{S}^{(k)}}\right) \\
-\left(\varphi_{C O_{2}, A C}^{(k)}\right)^{2} \exp \left(-\left(1-\alpha_{o x 2,+}\right) n_{o x 2} \frac{\Delta \phi_{A, o x 2}^{(k)}}{\vartheta_{S}^{(k)}}\right)
\end{array}\right\}
\end{gathered}
$$

and the electrochemical reduction of oxygen (red) at the cathode [12].

$$
r_{\text {red }}^{(k)}=\exp \left(A r r_{\text {red }} \cdot\left(\frac{1}{\vartheta_{\text {red }}^{\theta}}-\frac{1}{\vartheta_{S}^{(k)}}\right)\right) \cdot\left\{\begin{array}{c}
\left(\varphi_{C O_{2}, C C}^{(k)}\right)^{-2} \exp \left(2.5 \frac{\Delta \phi_{C, r e d}^{(k)}}{\vartheta_{S}^{(k)}}\right) \\
-\left(\varphi_{O_{2}, C C}^{(k)}\right)^{0.75}\left(\varphi_{C O_{2}, C C}^{(k)}\right)^{-0.5} \exp \left(-0.5 \frac{\Delta \phi_{C, r e d}^{(k)}}{\vartheta_{S}^{(k)}}\right)
\end{array}\right\}
$$

\section{Numerical Solution}

The model is solved using COMSOL Multiphysics Version 3.5 [21]. Taking into account all equations, the symmetric stack model consists of 114 PDEs and 26 ODEs as well as a number of algebraic equations. These equations are highly coupled to each other due to the connection of the gas compartments via the gas flow, the thermal interactions between all parts of the fuel cell, especially in stack direction, and the coupling of the electrochemical reaction rates at the anode and cathode of each fuel cell. Using a 6x6 mapped mesh and Lagrange-Quadratic elements, the discretized model has 19.292 degrees of freedom. To reduce the numerical effort, a coarser mesh is used to obtain initial solutions, before the fine mesh is employed to calculate the final solution. The UMFPACK direct solver is used.

The calculation time required to solve the symmetric stack model is about 15 minutes on a Dual Intel Xeon CPU 3.20GHz. Up to 3.5 GB RAM are needed to calculate a solution.

\section{Simulation Results}

In this section, selected results from the steady state simulation of the symmetric stack model with one half reforming unit and four fuel cells are presented in order to demonstrate the functionality and potential of the model. First, a set of input parameters, the so-called base case, is defined (Table 2). The base case conditions correspond to the values of the operating point 4 with an average current density of $i_{\text {avg }}=80 \frac{\mathrm{mA}}{\mathrm{cm}^{2}}$ used in the model validation by Gundermann et al. [17,22]. The feed gas composition corresponds to a mixture of methane and steam with a steam to carbon ratio of about 2.4 which has been reformed in the external reformer to about $20 \%$ conversion. In contrast to the work of Gundermann et al., the symmetric stack model considers the stack direction as an additional coordinate, i.e. the impact of a temperature profile along the stack length is shown by the simulation results. 
In the following, the simulated results of the gas composition within the reforming unit, the anode channels and the cathode compartments are discussed. Afterwards, the current densities for the four fuel cells are presented. This is followed by a discussion of the temperature distribution within the solid phases and the resulting temperature profile in stack direction. At the end of this section, the results of the symmetric stack model are compared to the results of the validated model by Gundermann et al..

This model has been derived based on a HotModule system build by MTU Onsite Energy, Germany. The simulation results reflect one of its operating points. In order to protect the intellectual property of our industrial partner we omit any absolute values in the following sections. However, we discuss the results qualitatively and draw some conclusions from that.

\subsection{Gas composition}

Figures 4 to 6 show some profiles of the molar fractions in the symmetric stack model. Within the reforming unit and the anode compartments, especially the methane molar fraction (Fig. 4) and the hydrogen molar fraction (Fig. 5) are of interest, while in the cathode channels, the molar fraction of carbon dioxide (Fig. 6) is important.

The molar fraction of methane within the non-reactive phase of the reforming unit and in the anode channels is shown in Fig. 4. Within the reforming unit, about $30 \%$ of the methane present at the inlet is converted to hydrogen. The chemical equilibrium, taking into account the local gas temperature, is reached within the reactive phase. Due to the mass transport limitation across the phase interface, equilibrium is not achieved in the non-reactive phase. Within the anode channels, the reforming products are continuously consumed by the electrochemical oxidation, so the methane concentration reaches virtually zero at the anode outlets.

Fig. 5 shows the hydrogen molar fraction in the reforming unit and the four fuel cells. Within the reforming unit, methane is converted to hydrogen by the methane reforming reaction. Hence, the hydrogen molar fraction increases to approximately one third at the outlet of the reforming unit. In the anode gas compartments, two processes occur. On the one hand, hydrogen is produced by the reforming process, on the other hand, hydrogen is consumed by the electrochemical reactions. Thus, the hydrogen molar fraction within the anode slightly increases near the anode gas inlet and after that decreases towards the gas outlet. The high concentration of hydrogen at the anode inlet also results in high electrochemical reactions rates at this point.

The hydrogen molar fraction is especially low at the anode outlet of cell 1 compared to the hydrogen molar fraction at the outlets of the other fuel cells. Considering the methane molar fraction, an inverse characteristic can be observed. This can be attributed to the lower temperatures in cell 1 due to the neighboring reforming unit. As result, the rates of the reforming reactions within the anode gas compartment are reduced and the equilibrium of these reactions is moved towards the educts.

Carbon dioxide is an important reactant for the electrochemical reduction reaction in the cathode channels. Its molar fraction is shown in Fig. 6. At the cathode inlet, the molar fraction of carbon dioxide is only a few mole percent. Along the channels, carbon dioxide is consumed in the electrochemical reaction. The consumption is higher in the lower cathode channels due to higher electrochemical reactions rates. This almost leads to depletion of carbon dioxide near the bottom left corner, where the anode inlet and the cathode outlet are located. Due to the fact that carbon dioxide is needed as an educt for the electrochemical reduction, its concentration, especially at this point, is critical for higher fuel utilization.

\subsection{Current density distribution}


Fig. 7 presents the current densities for the four fuel cells with an average cell current density of $i_{\text {cell }}=80 \frac{\mathrm{mA}}{\mathrm{cm}^{2}}$ as defined for the base case. All profiles are similar to each other. The maximum difference in local current density between two neighboring cells is less than $\Delta i=10 \frac{\mathrm{mA}}{\mathrm{cm}^{2}}$, although they are calculated independently. This means that the currents flowing through the bipolar plates in perpendicular direction to the stacking direction $\left(\zeta_{1}\right.$ and $\left.\zeta_{2}\right)$ are small. Therefore also the gradients in electric potential in the bipolar plates are small. Thus, the assumption of independent electric potentials for each cell (Section 3.1) is justified.

The rate of the electrochemical reactions, and therefore also the local current density, mainly depends on the concentration profiles of the educts of these reactions. Especially the concentrations of hydrogen in the anode channels and carbon dioxide in the cathode channels govern the current density distribution significantly. Due to the high concentration of hydrogen at the anode inlet, the highest current densities can be found in this region.

According to the superoxide reaction mechanism (Prins-Jansen et al. [23,24]), a negative order of reaction with respect to carbon dioxide is used for the cathodic reduction kinetics. Thus, the current density increases towards the end of the cathode channel, where the carbon dioxide fraction is low. Therefore, the current density peak is located in the vicinity of the anode inlet / cathode outlet, the bottom left corner of each fuel cell.

The main difference in the current density profiles of the four cells is the peak current density. The strong cooling effect in the upper half of cell 1 due to the reforming process in the IIR unit results in lower current densities in this part of the cell. But because the total cell current is given, this decreased current density in the upper half has to be compensated by high current densities in the peak region. There, the current density reaches values of more than twice the average value.

In opposite, the temperatures in cell 4 are generally higher due to the reduced effect of the cooling by the IIR unit.Thus the current density distribution is more homogeneous in this cell.

\subsection{Temperature distribution}

The temperature distribution within the solid phases of the four fuel cells is shown in Fig. 8. Temperatures are around $600{ }^{\circ} \mathrm{C}$, with a maximum temperature difference of approximately $100^{\circ} \mathrm{C}$.

In each cell, the highest temperature is located near the same corner where the current density peak is observed. This is mainly because of two reasons. First, the high local current density results in a strong heat source in that area due to losses in the electrochemical reactions and due to the ion conduction. The second reason for the location of the temperature peak is that the cooling effect of the IIR unit is especially strong in the upper half of the symmetric stack model, which effectively lowers the cell temperature there.

The cooling effect of the reforming unit becomes evident when comparing the temperature profiles of the four fuel cells. While the temperatures are generally lowest in cell 1, highest temperatures are predicted in cell 4, which is farthest away from the Indirect Internal Reforming unit. This results in an approximately parabolic temperature profile in stack direction.

The temperature levels between the four fuel cells $\left(T_{S, \min }, T_{S, \text { avg }}\right.$ and $\left.T_{S, \max }\right)$ differ by several $10^{\circ} \mathrm{C}$ (Fig. 9). Compared to the typical temperature difference in each cell, this gradient along the stack direction is significant. However, it seems that the temperature differences over each individual cell are nearly constant. So, although each cell operates at a significantly different temperature level, each cell has nearly the same temperature difference within the cell area. 
With respect to cell voltages, an increase by several $10 \mathrm{mV}$ from the first fuel cell to the fourth fuel cell is observed. This is clearly an effect of the cell temperature. A comparison between the cell voltages and the cell temperatures shows a similar slope, indicating a clear dependency between these values.

From these observations, two conclusions can be drawn. First, the individual fuel cells show very similar states with respect to gas composition, voltage and current density. A reduction of the stack model to a model with one single representative cell, as in Gundermann et. al. [13] is acceptable, if only these states are of interest. Second, concerning the cell temperature, the four cells show significant differences here. Especially for design and optimization purposes, where these values are considered important, the temperature profile in stack direction should not be neglected. For these applications, the stack model is a useful tool.

\subsection{Comparison to the validated model}

The load case shown here has previously been used by Gundermann et al. [17]. In their work, it was one of four load cases for which extensive sets of experimental data were available from a $250 \mathrm{~kW}_{\mathrm{el}}$ "HotModule" MCFC power plant manufactured by MTU Onsite Energy, Germany. These data sets were used to identify unknown parameters in a single cell model with an IIR unit. The single cell represented the average behavior of all cells in the stack. As a result, the deviation of the model by Gundermann et al. with respect to the experimental data was less or equal to the estimated measurement error, thereby validating the model [25]. To demonstrate the validity of our stack model, we compare some important values to those from the simulations of the previously validated model.

A variable which influences nearly all processes within the MCFC stack is the temperature of the solid phases. The temperature profiles show identical characteristics for both models with a maximum at the anode inlet / cathode outlet and a lower temperature in the top half of the fuel cells (see Fig. 8). A solid phase temperature between $T_{S, \min }=553{ }^{\circ} \mathrm{C}$ and $T_{S, \max }=642{ }^{\circ} \mathrm{C}$ was found in the validated simulations of Gundermann et al., which are well within the temperature range calculated for the symmetric stack model.

The current densities from both models show similar profiles (see Fig. 7). For the model of Gundermann et al., a maximum current density of $i_{\max }=164 \frac{\mathrm{mA}}{\mathrm{cm}^{2}}$ was found. According to the stack model, the maximum current density varies around this value. The cell voltage for both models is around $U_{\text {cell }}=0.80 \mathrm{~V}$, therefore the electric power generated by each cell as well as the efficiency of the MCFC system are nearly identical. Thus, the results of the new symmetric stack model correspond to those from the previously validated model and can be considered to adequately approximate the real stack behavior.

\section{Conclusions}

The symmetric stack model presented here allows the simulation of a representative section of a molten carbonate fuel cell stack. It consists of one half Indirect Internal Reforming unit and four fuel cells. The highly non-linear coupling of all parts of the stack, mainly due to the thermal interactions, the mass flow and the corresponding electrochemical reactions at the anode and the cathode of each fuel cell are taken into account.

The functionality of the model has been demonstrated using a steady state simulation based on validated model parameters. The model predicts the gas phase compositions, the temperature profiles and the current density distribution within each of the four fuel cells. The 
results of the symmetric stack model are similar to the simulation results of an earlier, validated model by Gundermann et al. [25].

The current density distributions for all cells in the stack show similar profiles. But due to the cooling effect of the reforming unit, the cell temperatures deviate by several $10^{\circ} \mathrm{C}$. As overheating is one of the reasons for degradation in an MCFC system, one may expect that cells 3 and 4 are degrading fastest in this stack.

Compared to the previous work, the model presented here takes into account the differences of the state variables within the fuel cells along the stack direction. It is shown that the temperature changes along this coordinate are significant with regard to the temperature differences within the cell planes. Therefore it is suitable for applications, where the treedimensional temperature profile within the stack should be considered.

Due to its generalized formulation, the model can easily be extended to different numbers of fuel cells. Furthermore, inhomogeneous gas feed distributions to the anode or cathode gas compartments of the different fuel cells as well as different gas flows for each fuel cell can be implemented. Additionally, the transient form of the model equations allows the simulation of load changes.

Considering the points listed above, the presented model gives the possibility to optimize design and operating parameters of MCFC systems with regard to homogenized temperature distributions and increased efficiency.

\section{Acknowledgment}

This work was financially supported by the MTU Onsite Energy - Fuel Cell Systems GmbH, Ottobrunn, Germany.

\section{Notation}

All listed variables are dimensionless quantities. The parameter values given here are valid for the symmetric stack model with one half reforming unit and four fuel cells.

\section{Latin letters}

$c$

$c_{\mathrm{p}_{i}}$
$c_{\mathrm{p}_{l}}$
$c_{\mathrm{p}_{S}}$
$D a_{j, l}$

$D_{i, l}$

$f_{R E C}$ capacity of charged double layers

$c_{A}=c_{E}=c_{C}=1 \cdot 10^{-5}$

molar heat capacity of component $i$

molar heat capacity of gas mixture in compartment $l$

molar heat capacity of solid phase

Damköhler number (reaction rate constant) of reaction $j$ in compartment $l$

$\begin{array}{cclc}D a_{\mathrm{ref} 1, I I R}^{R} & D a_{\text {ref } 2, I I R}^{R} & D a_{\text {ref } 1, A} & D a_{\text {ref } 1, A} \\ 800 & 800 & 200 & 200 \\ D a_{\text {ox } 1, A C} & D a_{\text {ox } 2, A C} & D a_{\text {red }, C C} & \\ 7 & 7 & 0.15 & \end{array}$

mass transport coefficient of component $i$ in gas compartment $l$

$D_{i, I I R}^{I} \quad D_{i, A C} \quad D_{i, C C}$

$16 \quad 100 \quad 100$

cathode gas recycle ratio 
stoichiometric factor electric current density total electric cell current geometric length ratio number of fuel cells mass exchange flux density of component $i$ number of exchanged electrons of reaction $j$ total mass exchange flux density electric power of the blower Peclet number (heat conduction resistance) of solid phase $P e_{S}=2.5$

surface related heat flux density heat source density in solid phase heat flux density between two solid phases heat flux density in stack direction heat flux reaction rate of reaction $j$ in gas compartment $l$ Stanton number (heat exchange coefficient)

\begin{tabular}{|c|c|c|c|c|c|c|c|}
\hline$S t_{I I R S}^{N}$ & $S t_{I I R S}^{R}$ & $S t_{I I R}^{I}$ & $S t_{H E}$ & $S t_{R A C}$ & $S t_{A S}$ & $S t_{C S}$ & $S t_{S}$ \\
\hline 200 & 200 & 60 & 200 & 2 & 40 & 140 & 100 \\
\hline
\end{tabular}

\section{Greek letters}

\section{$\gamma$}

$\Gamma$

$\Delta_{C} h_{i}^{\theta}$

$\Delta_{R} h_{j}^{\theta}$

$\varepsilon$

$\zeta$

$\vartheta$

$\vartheta^{r}$

$\kappa_{E}$

$v_{i, j}$

$\bar{v}_{j}$

$\tau$

$\varphi_{i}$

$\phi$

$\chi_{i}$

molar flow density (per cross-sectional area) in channels molar flow

standard enthalpy of combustion of component $i$

standard enthalpy of reaction $j$

volume fraction $\left(\varepsilon_{I I R}^{N}=0.75, \varepsilon_{I I R}^{R}=0.20, \varepsilon_{I I R}^{P}=0.05\right)$

spatial coordinate

temperature

reference temperature

ion conductivity in electrolyte $\left(\kappa_{E}=1\right)$

stoichiometric coefficient of component $i$ in reaction $j$

sum of stoichiometric coefficients of reaction $j$

time

partial pressure of component $i$ in electrode pores

electric potential

molar fraction

\section{Subscripts}




\section{Superscripts}

$+\mid-$
$\theta$
$S$
$L$
$I$
$N$
$R$

component index

reaction index

cell index

compartment index

total

$I I R|A| S \mid C \quad$ compartments: reforming unit, anode, solid, cathode

$A C \mid C C$

$B \mid R A C$

$H E A \mid H E B$

$A S \mid C S$

$I N|A I R| R E C$

ref $1 \mid \operatorname{ref} 2$

ox $1 \mid$ ox 2

red

in $\mid$ out

cell $\mid$ stack

diff | conv compartments: combustion chamber, reversal chamber compartments: heat exchanger (A: cold side; $\mathrm{B}$ : hot side)

interface: anode/solid, cathode/solid

gas flows: inlet, air, cathode gas recycle

reactions: methane steam reforming, water-gas shift reaction reactions: hydrogen oxidation, carbon monoxide oxidation reactions: oxygen reduction inlet, outlet one cell, entire stack diffusive, convective

\section{References}

[1] P. Tomczyk, Journal of Power Sources 2006, 160, 858

[2] M. Bischoff, Journal of Power Sources 2006, 160, 842

[3] N. Woudstra, T. van der Stelt, K. Hemmes, Journal of Fuel Cell Science 2006, 3, 155

[4] T. Watanabe, Y. Izaki, Y. Mugikura, H. Morita, M. Yoshikawa, M. Kawase,

F. Yoshiba, K. Asano, Journal of Power Sources 2006, 160, 868

[5] F. Yang, X.-J. Zhu, G.-Y. Cao, Journal of Power Sources 2007, 164, 713

[6] F. Yang, X.-J. Zhu, G.-Y. Cao, Journal of Power Sources 2007, 166, 354

[7] L.-j. Yu, G.-p. Ren, X.-m. Jiang, Energy Conversion and Management 2008, 49, 873

[8] P. Iora, S. Campanari, Journal of Fuel Cell Science and Technology 2007, 4, 501

[9] M. Baranak, H. Atakuel, Journal of Power Sources 2007, 172, 831

[10] M. Fermeglia, A. Cudicio, G. DeSimon, G. Longo, S. Pricl, Fuel Cells 2005, 5, 66

[11] P. Heidebrecht, Ph.D. Theses, Otto-von-Guericke University, Magdeburg, Germany, 2005

[12] P. Heidebrecht, K. Sundmacher, Journal of the Electrochemical Society 2005, 152, A2217

[13] M. Gundermann, P. Heidebrecht, K. Sundmacher, Fuel Cells 2008, 8, 96

[14] J. Brouwer, F. Jabbari, E. M. Leal, T. Orr, Journal of Power Sources 2006, 158, 213

[15] M. Sheng, M. Mangold, A. Kienle, A strategy for the spatial temperature control of a molten carbonate fuel cell system, JOURNAL OF POWER SOURCES 
162 (2, Sp. Iss. SI) (2006) 1213-1219.

[16] P. Heidebrecht, K. Sundmacher, Industrial \& Engineering Chemistry Research 2005, 44, 3522

[17] M. Gundermann, P. Heidebrecht, K. Sundmacher, Industrial \& Engineering Chemistry Research 2008, 47, 2728

[18] M. Pfafferodt, P. Heidebrecht, K. Sundmacher, U. Wuertenberger, M. Bednarz, Industrial \& Engineering Chemistry Research 2008, 47, 4332

[19] A. Musa, H. J. Steeman, M. De Paepe, Journal of Fuel Cell Science and Technology 2007, 4, 65

[20] M. Pfafferodt, P. Heidebrecht, K. Sundmacher, Computers \& Chemical Engineering, in preparation.

[21] COMSOL Multiphysics Reference Manual (Version 3.5), Stockholm, COMSOL $3.5,2008$

[22] M. Gundermann, Ph.D. Thesis, Otto-von-Guericke University, Magdeburg, Germany, 2008

[23] J. A. Prins-Jansen, K. Hemmes, J. H. W. de Wit, Electrochimica Acta 1997, 42, 3585

[24] J. A. Prins-Jansen, K. Hemmes, J. H. W. de Wit, Electrochimica Acta 1997, 42, 3601

[25] M. Gundermann, P. Heidebrecht, K. Sundmacher, Journal of Fuel Cell Science and

Technology 2006, 3, 303 
Tables

Table 1 Definition of important dimensionless variables.

$\begin{array}{lll}\text { Variable } & \text { Definition } & \begin{array}{l}\text { Standard value } \\ \text { temperature }\end{array} \\ \vartheta=T / T^{\theta} & \text { with } T^{\theta}=298.15 \mathrm{~K} \\ \text { current density } & I=\tilde{I} / I^{\theta} & \text { with } I^{\theta}=1406.4 \mathrm{~A} \\ \text { molar flow } & \Gamma=G / G^{\theta} & \text { with } G^{\theta}=6.377 \times 10^{-3} \mathrm{~mol} / \mathrm{s} \\ \text { voltage } & U=\tilde{U} / \phi^{\theta} & \text { with } \phi^{\theta}=0.0257 \mathrm{~V}\end{array}$


Table 2 Input Parameters of the symmetric stack model at base conditions.

$\begin{array}{lll}\begin{array}{l}\text { description } \\ \text { feed gas }\end{array} & \text { variable } & \text { dimensionless value } \\ \text { molar flow } & \Gamma_{I N} & 3.30 \text { (approx. 60\% fuel utilisation) } \\ \text { temperature } & \vartheta_{I N} & 2.18\left(=366^{\circ} \mathrm{C}\right) \\ \text { methane molar fraction } & \chi_{\mathrm{CH}_{4}, I N} & 0.22 \\ \text { water molar fraction } & \chi_{\mathrm{H}_{2} \mathrm{O}, I N} & 0.57 \\ \text { hydrogen molar fraction } & \chi_{\mathrm{H}_{2}, I N} & 0.15 \\ \text { carbon monoxide molar fraction } & \chi_{\mathrm{CO}_{I N}} & 0.00 \\ \text { carbon dioxide molar fraction } & \chi_{\mathrm{CO}_{2}, I N} & 0.05 \\ \text { air } \quad & \Gamma_{A I R} & 21.96\left(\lambda_{A I R}=2.56\right) \\ \text { molar flow } & \vartheta_{A I R} & 1.08\left(=43^{\circ} \mathrm{C}\right) \\ \text { temperature } & \chi_{\mathrm{O}_{2}, I N} & 0.21 \\ \text { oxygen molar fraction } & \chi_{\mathrm{N}_{2}, I N} & 0.79 \\ \text { nitrogen molar fraction } & I_{c e l l} & 0.45\left(80 \mathrm{~mA} / \mathrm{cm}^{2}\right) \\ \text { total cell current } & P_{b l o w e r} & 2.775(100 \mathrm{~W} / \mathrm{cell} \\ \text { electric power of the blower per cell } & f_{R E C} & 0.70 \\ \text { cathode gas recycle ratio } & \end{array}$




\section{Figures Caption}

Fig. 1 Working principle of the considered Molten Carbonate Fuel Cell system.

Fig. 2 Structure and gas flows in the symmetric MCFC stack model, consisting of four fuel cells and one half IIR unit.

Fig. 3 Structure of the model for the reforming unit consisting of the reactive phase (index $N$ ) and the non-reactive phase (index $R$ ). All states, fluxes and inlet/outlet conditions are indicated.

Fig. 4 Methane molar fraction in the non-reactive phase of the reforming unit (IIR) and in the anode gas channels of the four fuel cells. The flow direction within the gas compartments is indicated by the arrows.

Fig. 5 Hydrogen molar fraction within the reforming unit (IIR) and the anode gas compartments of the four fuel cells. The arrows indicate the flow direction of the gas.

Fig. 6 Molar fraction of carbon dioxide within the cathode gas compartments of the four fuel cells. The gas flow is indicated by the arrows.

Fig. 7 Current densities within the four fuel cells. The flow directions of the anode and cathode gases are indicated by the arrows.

Fig. 8 Temperature profile within the solid phases of the four fuel cells. The reforming unit $(I I R)$, where the endothermic reforming reaction takes place, is located on the left hand side of the first cell. The flow direction within the anode and cathode gas compartments are indicated by the arrows.

Fig. 9 Minimum, average and maximum temperature within the solid phase of the four fuel cells (top) and the cell voltages (bottom). 


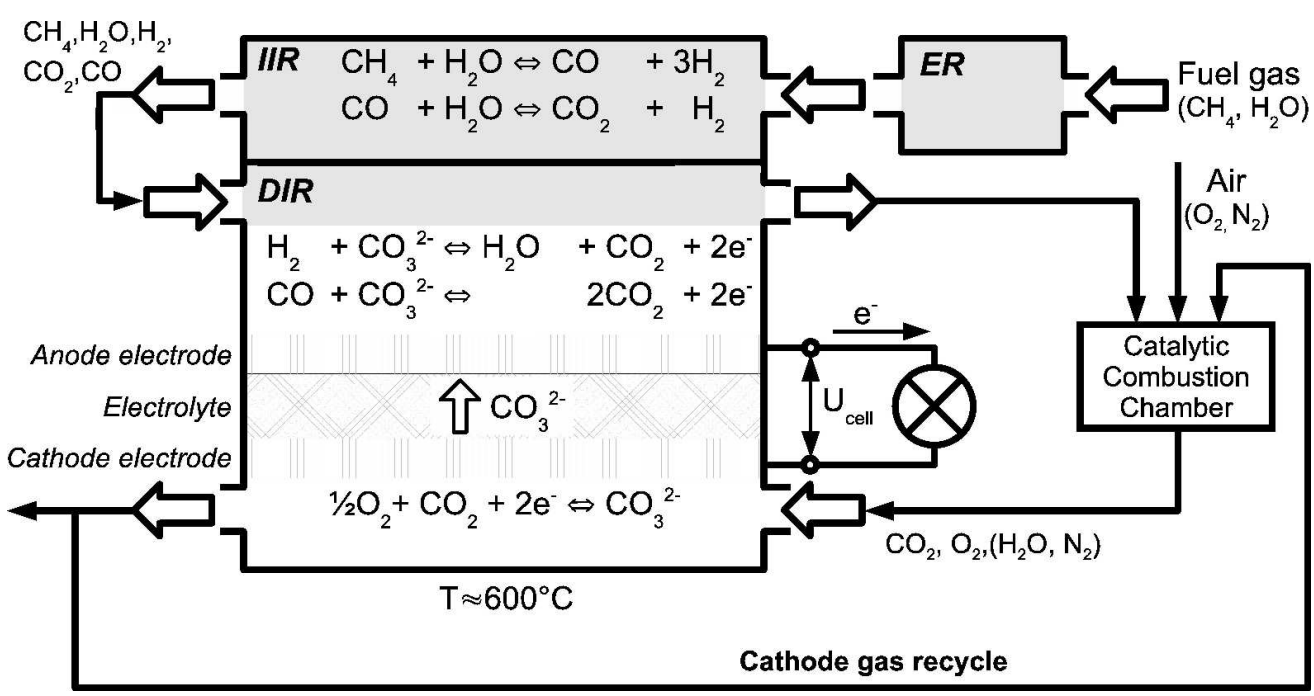

Working principle of the considered Molten Carbonate Fuel Cell system. $200 \times 103 \mathrm{~mm}(600 \times 600 \mathrm{DPI})$ 


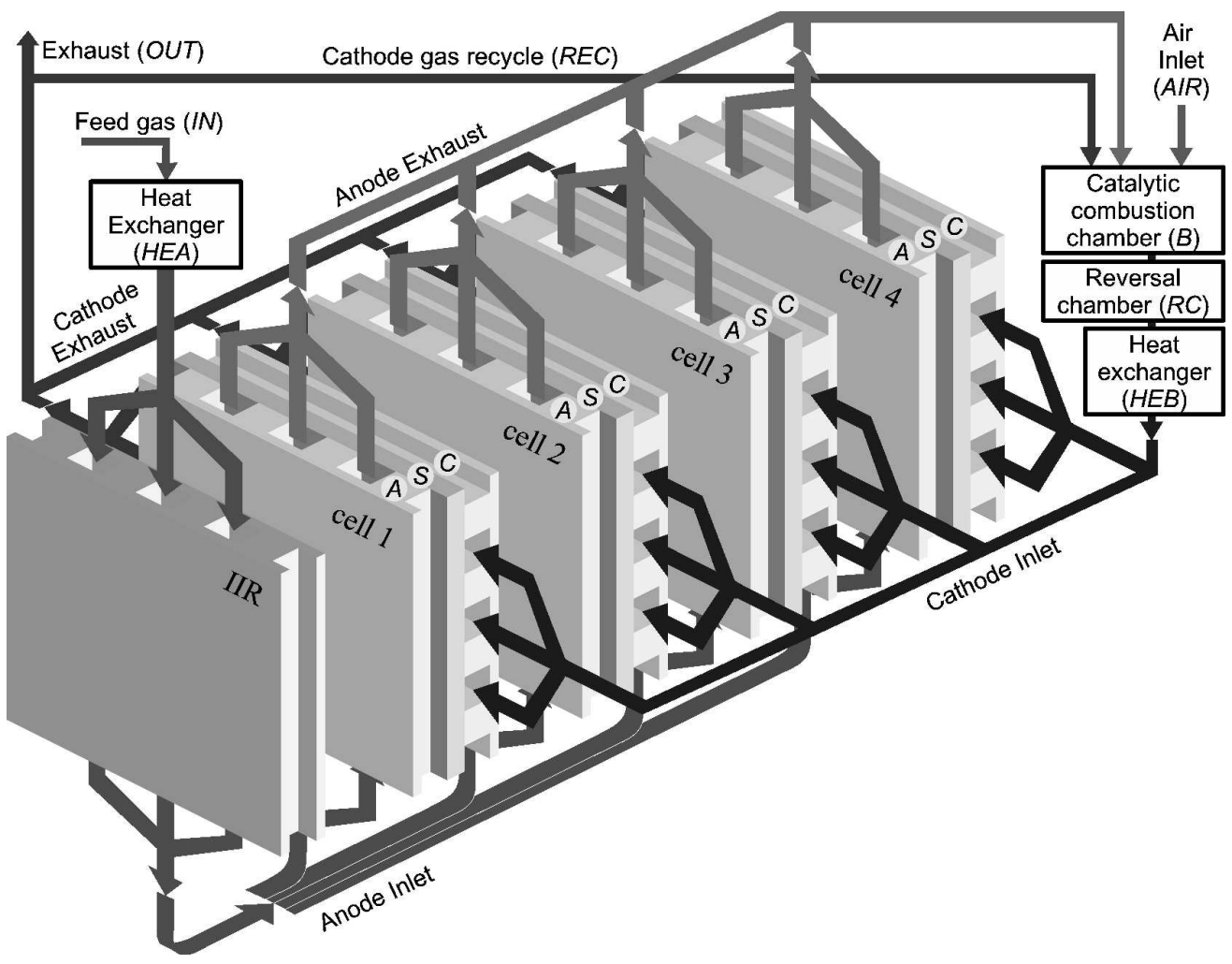

Structure and gas flows in the symmetric MCFC stack model, consisting of four fuel cells and one half IIR unit.

$284 \times 220 \mathrm{~mm}(600 \times 600$ DPI $)$ 


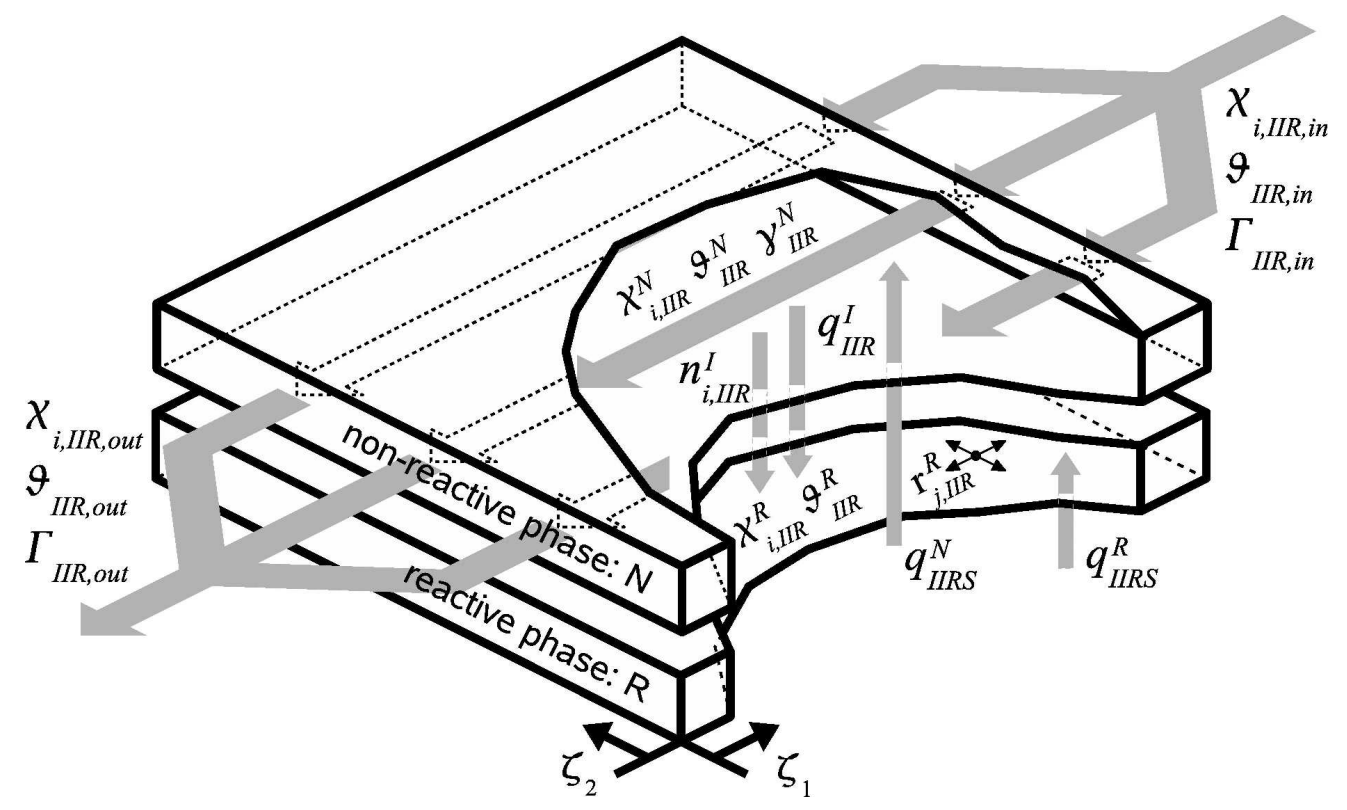

Structure of the model for the reforming unit consisting of the reactive phase (index $R$ ) and the non-reactive phase (index $\mathrm{N}$ ). All states, fluxes and inlet/outlet conditions are indicated. $158 \times 95 \mathrm{~mm}(600 \times 600 \mathrm{DPI})$ 


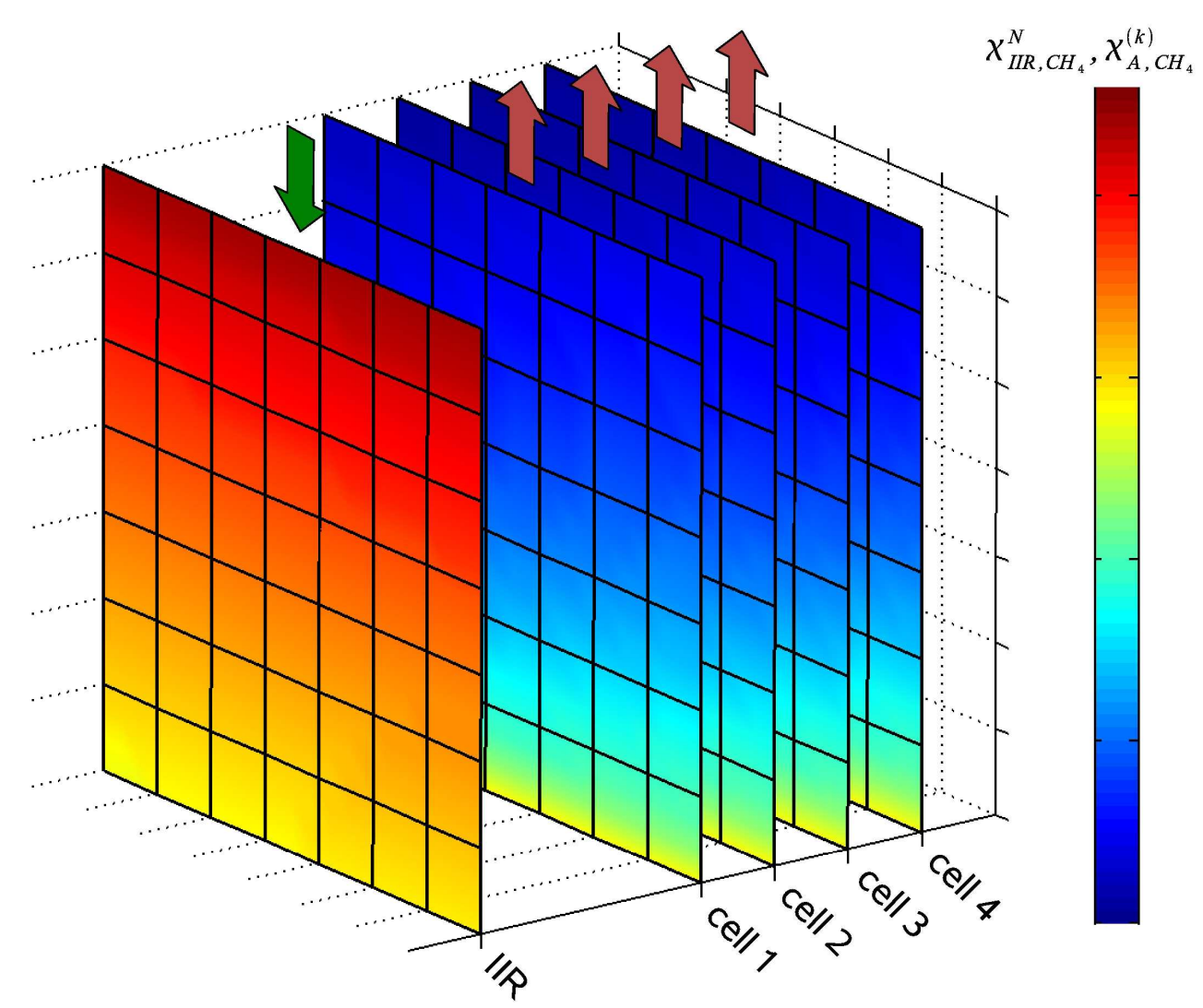

Methane molar fraction in the non-reactive phase of the reforming unit (IIR) and in the anode gas channels of the four fuel cells. The flow direction within the gas compartments is indicated by the arrows. 


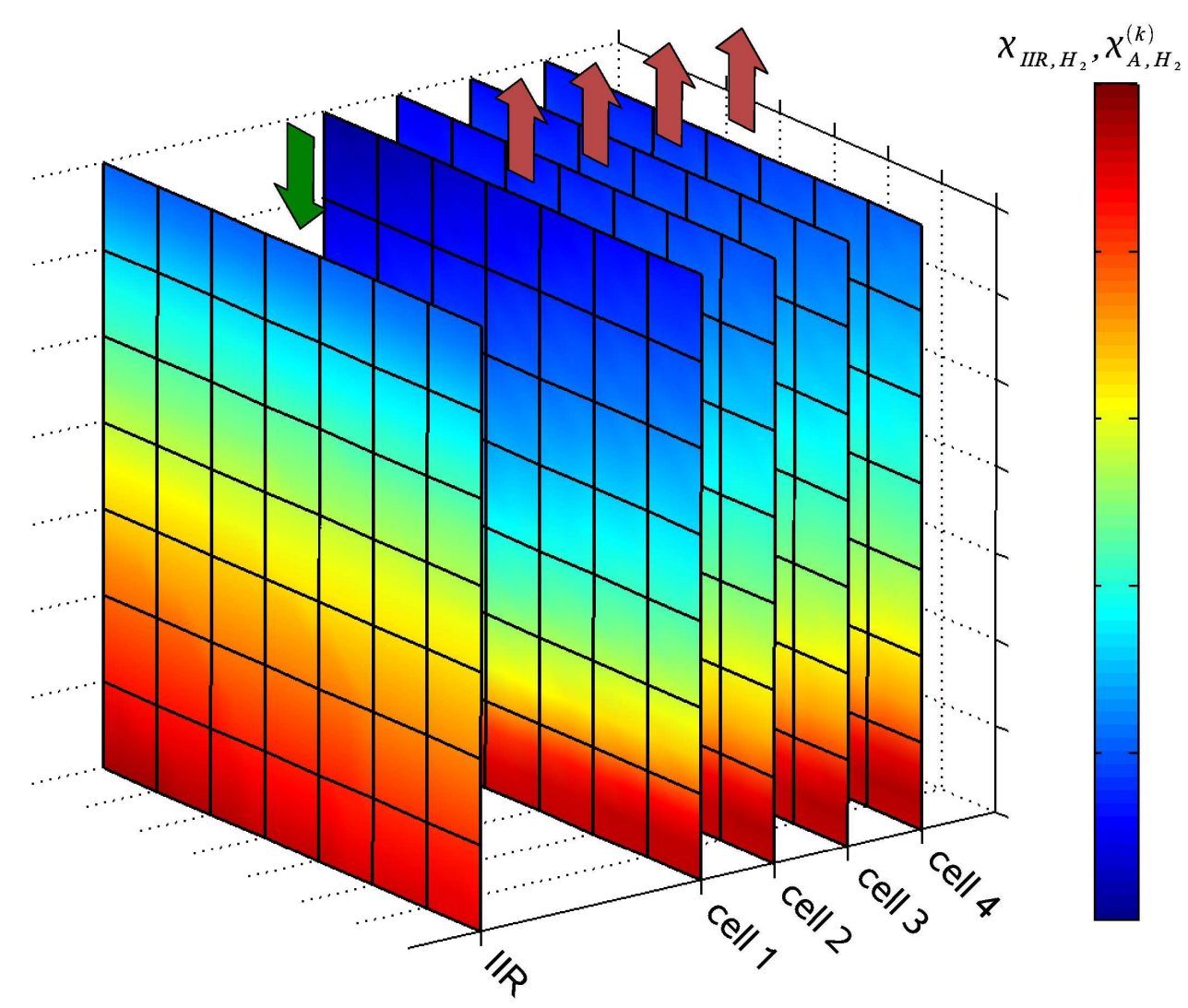

Hydrogen molar fraction within the reforming unit (IIR) and the anode gas compartments of the four fuel cells. The arrows indicate the flow direction of the gas. $186 \times 152 \mathrm{~mm}(600 \times 600 \mathrm{DPI})$ 


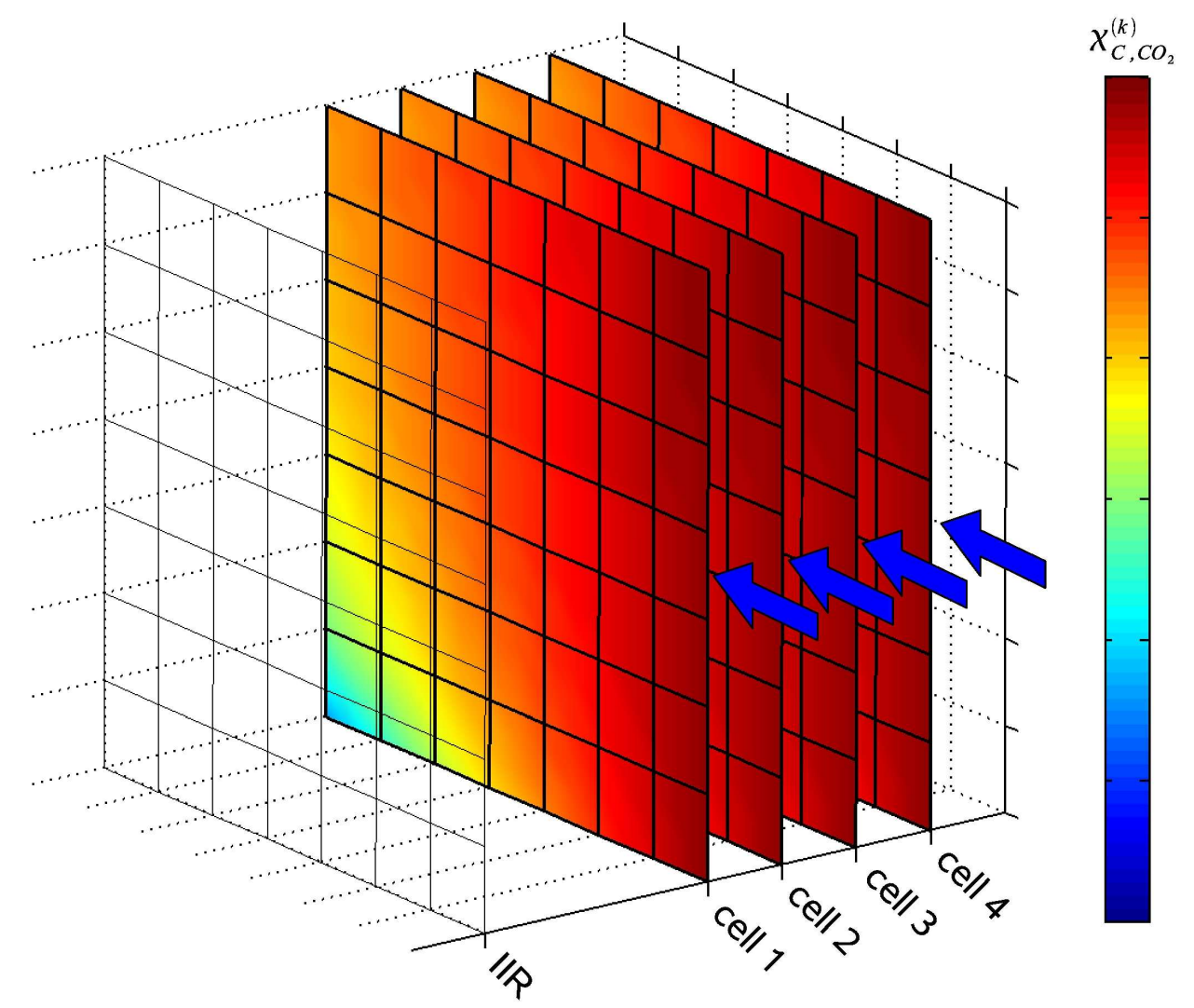

Molar fraction of carbon dioxide within the cathode gas compartments of the four fuel cells. The gas flow is indicated by the arrows. $186 \times 152 \mathrm{~mm}(600 \times 600 \mathrm{DPI})$ 

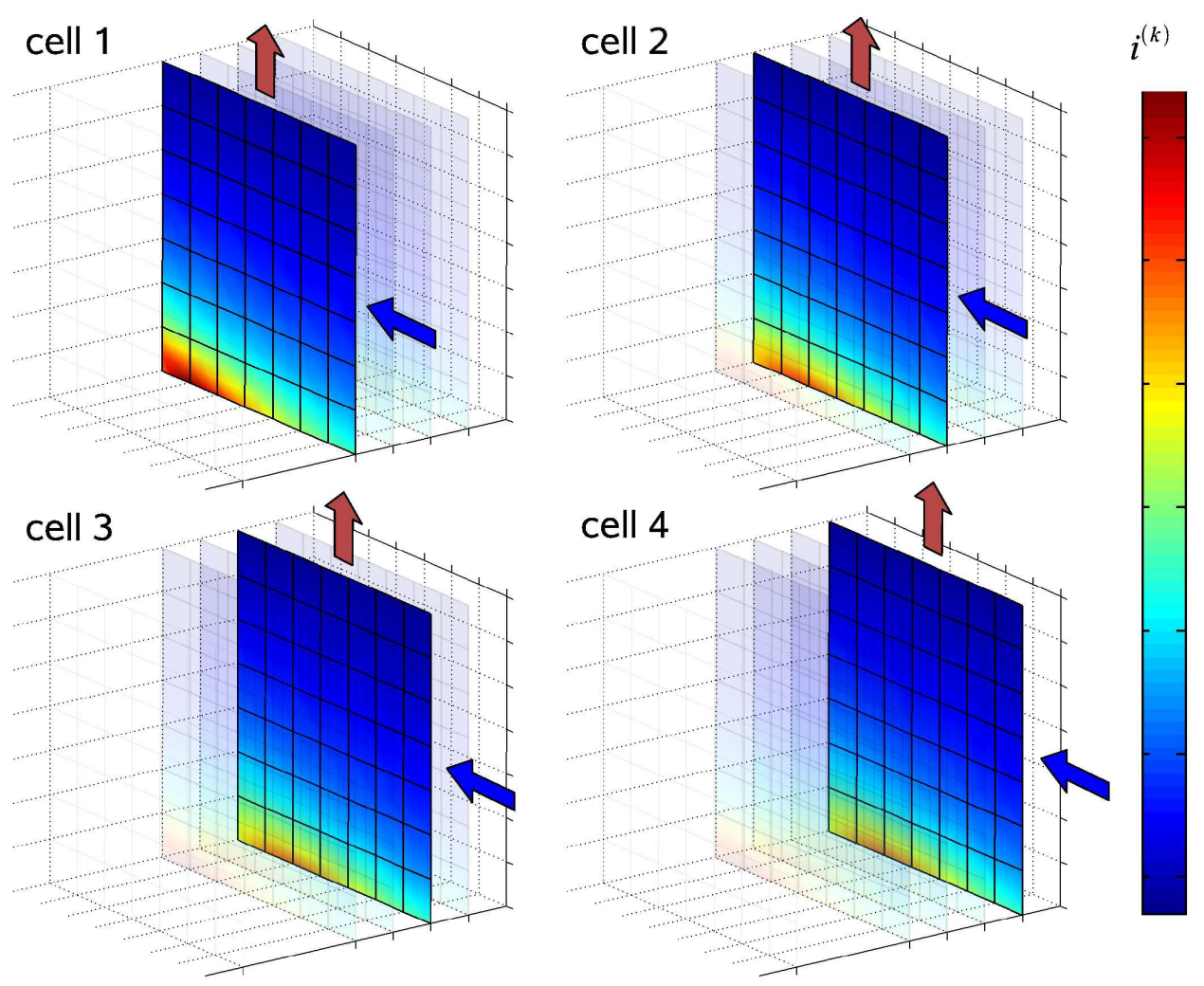

Current densities within the four fuel cells. The flow directions of the anode and cathode gases are indicated by the arrows. $184 \times 147 \mathrm{~mm}(600 \times 600 \mathrm{DPI})$ 

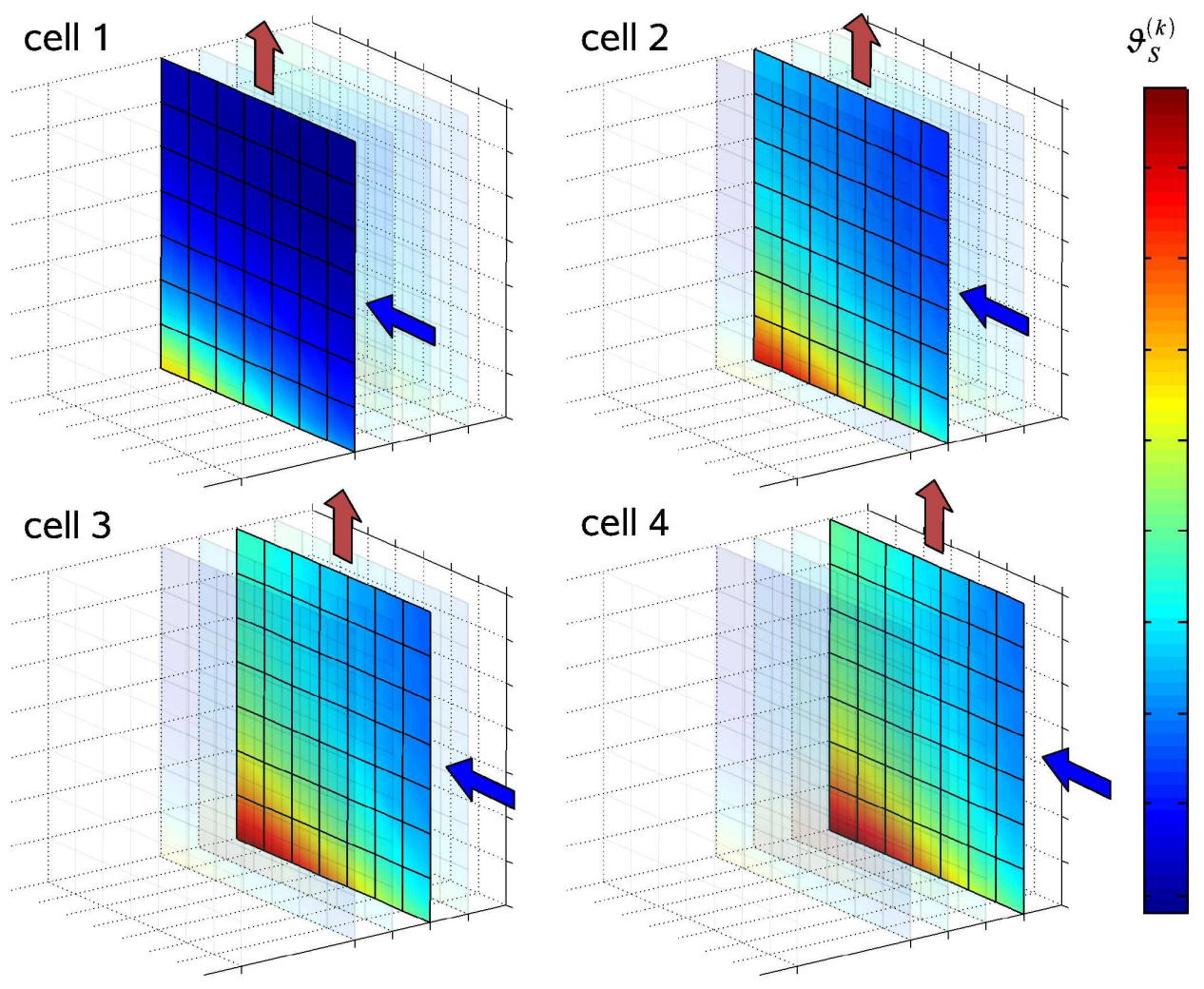

Temperature profile within the solid phases of the four fuel cells. The reforming unit (IIR), where the endothermic reforming reaction takes place, is located on the left hand side of the first cell. The flow direction within the anode and cathode gas compartments are indicated by the arrows. $184 \times 147 \mathrm{~mm}(600 \times 600 \mathrm{DPI})$ 
Minimum, average and maximum temperature within the solid phase of the four fuel cells (top) and the cell voltages (bottom). $180 \times 192 \mathrm{~mm}(600 \times 600 \mathrm{DPI})$
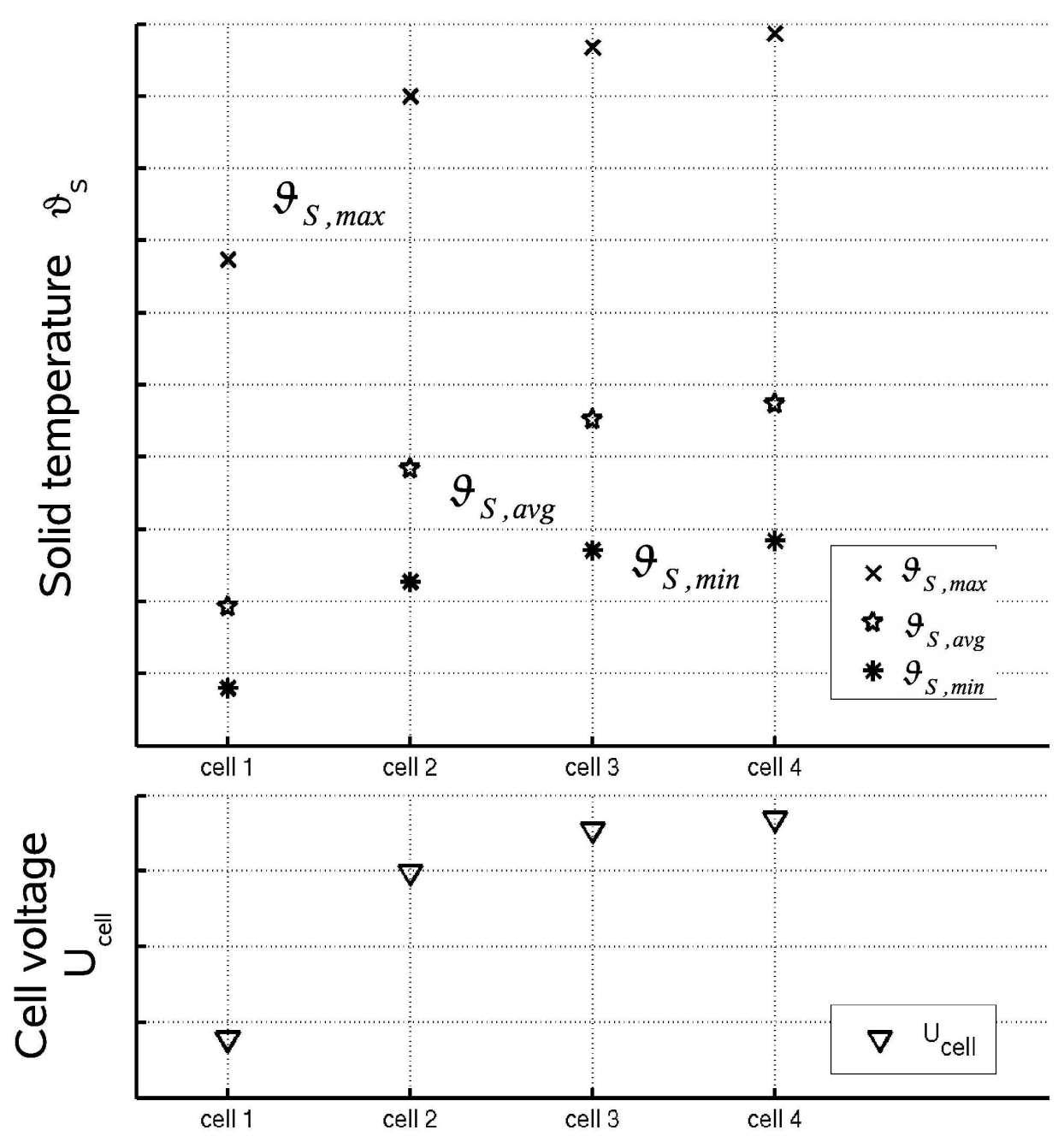